\title{
Application of Nanofluids for Cooling Newtonian and Non-newtonian Blood Mimicking Fluids Flow in Annular Space
}

\author{
Abdulhassan Abed Karamallah, Kadhum Audaa Jehhef \\ Mechanical Engineering Department, University of Technology, Baghdad, Iraq \\ Email address: \\ dr_abdulhassank@yahoo.com (A. A. Karamallah),kadhum.audaa@yahoo.com (K. A. Jehhef)
}

\section{To cite this article:}

Abdulhassan Abed Karamallah, Kadhum Audaa Jehhef. Application of Nanofluids for Cooling Newtonian and Non-Newtonian Blood Mimicking Fluids Flow in Annular Space. Engineering and Applied Sciences. Vol. 2, No. 1, 2017, pp. 1-16. doi: 10.11648/j.eas.20170201.11

Received: January 26, 2017; Accepted: February 10, 2017; Published: March 4, 2017

\begin{abstract}
An experimental study performed to investigate the effect of nanofluid forced convection heat transfer and fluid flow characteristic. Three types of nanofluids $\left\{\gamma \mathrm{Al}_{2} \mathrm{O}_{3}, \mathrm{CuO}\right.$ and $\mathrm{ZrO}_{2}$-DIW $\}$ flow under laminar or turbulent condition in inner pipe. The shear thinning behavior of blood is more accurately modeled by non-Newtonian Blood Mimic Fluids BMF. Here heat transfer and friction factor correlations developed for nonreactive Newtonian and non-Newtonian BMF fluids of (water: glycerol: xanthan gums) and heparinized bovine blood. The results show that the BMF Nussult number $\left(\mathrm{Nu}_{\mathrm{b}}\right)$ increased as increasing Graetz number, and as flow index (n) decreasing. Bovine blood gives the temperatures distribution similar to (BMF6) but with lower Nusselt number by (31.2\%). The BMF friction factor increases with decreasing (n), but the Bovine blood gives higher friction factor as compared with BMF6 by $(25.6 \%)$. It was observed that all nanofluids types showed higher heat transfer characteristics than the base fluid DIW. It was also noted that in the $\gamma \mathrm{Al}_{2} \mathrm{O}_{3}$ shows higher enhancement than the other by $(82.4 \%)$ at $\left(\operatorname{Re}_{n f}=12670\right)$ and $(\phi=1$ vol. $\%)$. Comparisons present experimental results with previously reported results it gives good agreement.
\end{abstract}

Keywords: Non-newtonian Fluids, Nanofluids, Hypothermia, Intravenous Cooling

\section{Introduction}

The heat transfer characteristics in blood heat exchangers BHE used in many medical applications for cooling biofluid such as blood, where recently the most effective hypothermia method used is intravenous cooling catheters inserted in the vena cava blood vessel (IVC) and by using water as the usual cooling or warming medium. The non-Newtonian blood flows in annular space between the blood vessel wall and cooling catheter studied by $[1,2]$. Convective heat transfer in double pipe systems can be enhanced in several ways, by using either active or passive techniques. The active case, is to modify the fluid itself by enhancing its thermal conductivity. Various techniques have been used to increase the thermal conductivity of base fluids by introducing solid particles whose conductivity is generally higher than that of liquids. New classes of fluids called Nanofluids have recently been developed, tested and studied by Sebastien et al. [3], Choi [4], Zeinali et al. [5], Anoop et al. [6] and Zhang et al. [7]. Byung et. al. [8] Aghayari et. al., [9], Sudarmadji, [10],
Mohamed et. al., [11] performed an investigation for the convective heat transfer coefficient of nanofluids made of several alumina nanoparticles and transformer oil flowing through a double pipe heat exchanger system in laminar nanofluids exhibited a considerable increase of heat transfer coefficients of alumina is much higher than that of the base fluids. Masoud et al. [12] studied the plate and concentric tube heat exchangers by using water-water and nanofluidwater streams. The $\mathrm{ZnO} /$ water $(0.5$ vol. \%) nanofluid has been used as the hot stream. They results show that heat transfer rate and heat transfer coefficients of the nanofluid is higher than that of the (water). In the concentric heat exchanger the heat transfer coefficient of nanofluid at $(\mathrm{m}=10 \mathrm{~g} / \mathrm{s})$ is about $(14 \%)$ higher than the base fluid. Bozorgan et al. [13] used nanofluids as coolant candidate in chemical processes for water waste remediation. The inlet and outlet temperatures of hot solvent stream are equal to $\left(40^{\circ} \mathrm{C}\right.$ and $\left.30^{\circ} \mathrm{C}\right)$, respectively. The flow rate of hot solvent stream is $\left(0.8 \mathrm{~kg} \mathrm{~s}^{-1}\right)$. The inlet temperature of nanofluid coolant is equal to $\left(5^{\circ} \mathrm{C}\right) . \mathrm{Al}_{2} \mathrm{O}_{3}$ nanoparticles dispersed in 
water with volume concentrations up to ( 2 vol. \%) were selected as a coolant. The results show that the flow rate of nanofluid coolant decreases with the increase of concentration of nanoparticles in the exchanger with a given heat exchange capacity.

The study of blood flow through an axisymmetric annular tube has been the subject of many studies, due to its relevance to blood flow in a catheterized artery studied by [14, 15, 16 and 17]. Dash et. al. [18] estimated the increased flow resistance in a narrow catheterized artery using the Casson fluid model. Banerjee et al. [19] investigated the changes in flow and mean pressure gradient across a coronary artery using power law and Carreau model, a shearrate-dependent non-Newtonian fluid model. Jason [20] models two dimensional, axis-symmetric, counter flows with two domains of the catheter balloon and the vena cava blood vessel. Implemented in COMSOL program to modeling the intravenous catheter cooling system, Chose to model both the vessel and the catheter as concentric cylindrical tubes for simplicity sake. His results show that whether increasing the length of catheter and decreasing the cooling fluid temperature or decreasing the length of the catheter and increasing the cooling fluid temperature reduces the treatment time significantly. Laminar flow with pseudoplastic and dilatant fluids (power-law models) was studied experimentally by [21, 22 and 23] studied the friction factors and heat transfer with power-law fluids with flow index of 0.5 to 1.0 . They showed that the friction factor increased with decrease in the flow index and he Nusselt number increased with decreasing flow indices (n) and Nusselt number increases with decreasing (n). The flow of non-Newtonian fluid in annulus also studied by [24, 25]. Very little work has been done in the experimental study the flow and thermal characterizations together of BMF flows in annular space and cools by nanofluid flows in inner pipe in double-pipe heat exchanger. In this study using simulation of human blood flow in annulus between the cooling catheter wall (inner pipe) and the IVC blood vessel wall (outer pipe) of the intravascular cooling catheter, to find the temperature distribution around the catheter, using two domains of the BMF and the effect of using nanofluids instead of DIW with opposite direction flows.

\section{Experimental Apparatus}

(Figure. 1) shows the schematic diagram of experimental loop, it consists of a test section, a two centrifugal pump, condensation unit with immersion coil and a heating unit. The test section is a $(1.0 \mathrm{~m})$ long counter flow double-pipes heat exchanger with DIW flows inside the inner pipe while hot BMF flows in the annular space. The inner tube is made from a non-corrosive medical suitable smooth stainless steel (SS 304) with external diameters $(10.05 \mathrm{~mm})$ and $(8.75 \mathrm{~mm})$. The outer tube is made from transparent plastic diameters of $(30.25 \mathrm{~mm})$ and $(23.45 \mathrm{~mm})$. The test section is thermally isolated from its upstream and downstream section by rubber plug, and thermally isolated on the external surface of the outer tube. Seven thermocouples are mounted at different longitudinal positions on the inner pipe surface. The inlet and exit temperatures of DIW and BMF are measured using four T-type thermocouples. Two receiver tanks of $(20 \mathrm{~L})$ are made from glass to store the BMF and nanofluids leaving the test section. The hot BMF flow rate are controlled by a flow meter (Model LD100, MLW, Germany) was used to initially adjust the desired flow rate in each experiment, but exact measurements were obtained by weighing fluid samples collected at determined time intervals. under the laminar condition only of (1-7 1/min), it calibrated to fit work with the non-Newtonian fluid flow, for nanofluid flow under laminar and turbulent conditions using flow meters of (0.3-0.8 1/min) and $(1.8-18 \mathrm{l} / \mathrm{min})$ respectively.

\section{BMF Sample Preparation}

In the preparation process of Newtonian (BMF1 and BMF2) models using fluids content the (water: Glycerin) mixture. By adding the DIW into (5 liters) beaker, and then add the glycerin liquid, the glycerin should try to settle down because it's high viscosity and density than the DIW. Water and glycerol are easily miscible so it will dilute easily and if they mixed gently with stirring they will miscible quickly using a mechanical agitation stirring for $(20 \mathrm{~min})$ until the solution is reaches the homogeneous state. But preparation process of non-Newtonian (BMF3 and BMF4) and (BMF5 and BMF6) models with a high rheological properties using two polymer types, the first consist of two BMF of (water: xanthan gum), the second BMF using include two BMF of (water: Glycerin: xanthan gum), where the ternary mixture water-glycerol-xanthan simulates the non-Newtonian rheological behavior of blood. was produced by filling the beaker of ( 5 liters) by specified weighted ratio of the DIW and adding the polymer powder lightly sprinkled into the water and stirring continued using the mechanical agitation stirring for about (one hour) to ensure completely polymer dissolution. The prepared BMF models was kept at rest at room temperature for $(24 \mathrm{hr})$ prior to conducting the measurements of rheological parameters (m) and (n) by power low of $\left(\tau=m(\gamma)^{n}\right)$ given by Brookfield DV-II+Pro coaxial rotational rheometer and using the Rheocalc software (version 3.2) for data acquisition and compared the parameters with [26, 27] and give good agreements. Thermophsical properties also measured and listed shows in (Table. 1). Also was used (3.0 liters) heparinized bovine blood with a hematocrit of (35\%). The blood is mixed gently every ( 5 minutes) to keep it homogenous. In the beginning of the first experiment, the blood is re-circulated for one minute through the primary reservoir to ensure that all components of the system work properly without loss of blood.

\section{Preparation of Nanofluid}

Three types of nanoparticles of (Alumina $\mathrm{Al}_{2} \mathrm{O}_{3}$, Copper Oxide $\mathrm{CuO}$ and Zirconia $\mathrm{ZrO}_{2}$ ) are used in this research. All thermophysical properties for the three types of the 
nanoparticle and the base fluid are given in (Table. 2). The Two-steps method is used for preparation of nanofluid. By using the electronic gram scale, to get the desired mass of nanopowder, the dispersant weighed powder $\left(\mathrm{Al}_{2} \mathrm{O}_{3}, \mathrm{CuO}\right.$ or $\mathrm{ZrO}_{2}$ ) nanoparticles were dissolved in the DIW. The volume of mixture (water/nanoparticles) was set at (3.0 liters). This mixture was mixed slowly in the sonicator that can be timed for a maximum of (15-20 minutes) to break up any particle aggregates. All the suspensions, that had an ink-like appearance, were stored at ambient temperature and checked periodically for visual changes. In this research during the experiments five volume concentrations $(0.02,0.06,0.2,0.6$ and 1.0 vol. \%) for $\left(\mathrm{Al}_{2} \mathrm{O}_{3}\right.$ and $\mathrm{CuO}$ and $\left.\mathrm{ZrO}_{2}\right)$. All thermophysical properties of these nanofluids employed are measured experimentally by using certificated instruments. (Figure. 2) show samples of $\left(\mathrm{ZrO}_{2}-\mathrm{DIW}, \mathrm{CuO}-\mathrm{DIW}, \gamma \mathrm{Al}_{2} \mathrm{O}_{3}-\right.$ DIW) nanofluids

Table 1. Thermophysical and rheological properties measurements of BMF and Bovine blood.

\begin{tabular}{llllll}
\hline BMF Model & Rheological Relation & Flow Index $(\mathbf{n})$ & Density $\rho\left(\mathbf{g} / \mathbf{m}^{\mathbf{3}}\right)$ & Specific heat $\mathbf{C}_{\mathbf{p}}(\mathbf{J} / \mathbf{k g ~ K})$ & Thermal conductivity W/m. K \\
\hline BMF1 & $\tau=0.00286(\gamma)^{\mathrm{n}}$ & 1.0 & 1.0321 & 3977.726 & 0.51586 \\
BMF2 & $\tau=0.00364(\gamma)^{\mathrm{n}}$ & 1.0 & 1.0124 & 3967.116 & 0.51076 \\
BMF3 & $\tau=0.01726(\gamma)^{\mathrm{n}}$ & 0.5643 & 0.5752 & 4244.126 & 0.53676 \\
BMF4 & $\tau=0.00241(\gamma)^{\mathrm{n}}$ & 0.3977 & 0.4123 & 4308.306 & 0.57466 \\
BMF5 & $\tau=0.02514(\gamma)^{\mathrm{n}}$ & 0.7921 & 0.8128 & 3305.726 & 0.52576 \\
BMF6 & $\tau=0.32612(\gamma)^{\mathrm{n}}$ & 0.5134 & 0.5573 & 3472.216 & 0.54736 \\
Bovine Blood & $\tau=0.26889(\gamma)^{\mathrm{n}}$ & 0.6319 & 0.7472 & 3893.355 & 0.52214 \\
\hline
\end{tabular}

Table 2. Nanoparticle and Base Fluid Properties.

\begin{tabular}{|c|c|c|c|c|c|}
\hline Particle & $\rho_{\mathrm{p}}\left(\mathrm{kg} / \mathrm{m}^{3}\right)$ & $k_{p}(W / m . C)$ & $\mathrm{cp}_{\mathrm{p}}(\mathrm{J} / \mathrm{kg} . \mathrm{C})$ & $d_{p}(n m)$ & Color \\
\hline$\gamma \mathrm{Al}_{2} \mathrm{O}_{3}$ & 3970 & 40 & 880 & 20 & white \\
\hline $\mathrm{CuO}$ & 6500 & 13.5 & 535.6 & 40 & black \\
\hline $\mathrm{ZrO}_{2}$ & 5680 & 2 & 418 & 80 & white \\
\hline Base fluid & $\rho_{\mathrm{f}}\left(\mathrm{kg} / \mathrm{m}^{3}\right)$ & $\mathrm{k}_{\mathrm{f}}(\mathrm{W} / \mathrm{m} . \mathrm{c})$ & $\mathrm{cp}_{\mathrm{f}}(\mathrm{J} / \mathrm{kg} . \mathrm{c})$ & $\mu_{\mathrm{f}}(\mathrm{nm})$ & \\
\hline DIW & 997.1 & 0.6017 & 4183 & 0.000957 & \\
\hline
\end{tabular}

\section{Data Reduction}

\subsection{BMF Calculations}

The heat transfer coefficients and pressure drop of BMF can be calculated from the following equations:

The heat transfer rate into the BMF is defined as:

$$
Q_{b}=\dot{m}_{b} C p_{b}\left(t_{\text {in }}-t_{\text {out }}\right)_{b}
$$

The heat transfer rate into the DIW is defined as:

$$
Q_{n f}=\dot{m}_{n f} C p_{n f}\left(t_{o u t}-t_{\text {in }}\right)_{n f}
$$

The average heat transfer rate is defined as follows:

$$
Q_{\text {ave }}=\frac{Q_{b+} Q_{n f}}{2}
$$

The experimental local heat transfer coefficient and Nusselt number of the BMF are computed from the following equations.

The convection BMF heat flux can be represented by:

$$
q_{b}=\frac{Q_{b}}{A_{i}}
$$

where $A_{i}$ is the heat transfer area given by:

$\mathrm{A}_{\mathrm{i}}=\pi \mathrm{d}_{\mathrm{i}} \mathrm{L}$

The BMF local heat transfer coefficient can be obtained as:

$$
\bar{h}_{b}=\frac{q_{b}}{\pi D_{i} L\left(t_{b}-t_{w x}\right)}
$$

And the BMF local Nusselt number can be obtained as:

$$
\bar{N} u_{b}(\exp )=\frac{\bar{h}_{b} D_{h}}{k_{b}}
$$

Where hydraulic diameter of annular space calculate as:

$$
D_{h}=\mathrm{D}_{\mathrm{i}}-d_{i}
$$

The experimental average heat transfer coefficient and Nusselt number of the BMF are computed from the following equation:

The BMF average heat transfer coefficient can be obtained as:

$$
h_{b}=\frac{q_{b}}{\left(t_{b}-t_{\text {wall }}\right)}
$$

Then the BMF average Nusselt number can be obtained as:

$$
N u_{b}=\frac{h_{b} D_{h}}{k_{b}}
$$

Similarly to the heat transfer coefficient, the friction factor of the BMF is calculated from:

$$
f_{b}=\frac{2 D_{h} \Delta P_{b}}{L \rho_{b} u_{b}^{2}}
$$

where $(\mathrm{fb})$ is the friction factor of the BMF, $\left(\Delta \mathrm{P}_{\mathrm{b}}\right)$ is the measured pressure drop of the BMF.

All BMFs employed in this study exhibit the power-law rheological behavior expressed by the following equation [28]:

$$
\tau=m(\dot{\gamma})^{n}
$$

In this work, the non-Newtonian fluids are based on a 
power-law equation (Eq.11). Values of $(\mathrm{n}<1)$ are shearthinning fluids and with $(\mathrm{n}>1)$ are shear-thickening fluids. For Newtonian fluids have $(\mathrm{n}=1)$. The shear stress is proportional with the fluid viscosity $(\mu)$ and $\operatorname{shear} \operatorname{strain}(\dot{\gamma})$. For power-law shear-thinning fluids the wall shear rate is: [29]

$$
\dot{\gamma}_{w a l l}=\frac{3 n+1}{4 n} \cdot \frac{8 u_{b}}{D_{h}}
$$

The effective viscosity at the wall shear rate is: [29]

$$
\mu_{\text {eff }}=m\left(\dot{\gamma}_{w a l l}\right)^{n-1}
$$

For purely viscous non-Newtonian fluid, Wickramasinghe et al. [30] define a generalized Reynolds, $\mathrm{Re}_{\mathrm{b}}$ for power law as follows

$$
\operatorname{Re}_{b}=\frac{\rho_{b} u_{b}^{2-n} D_{h}^{n}}{m} \cdot 8 \cdot\left(\frac{n}{6 n+2}\right)
$$

where $u_{b}$ is the average velocity of the shear-thinning fluid, which may be related to the average velocity of a Newtonian fluid by:

$$
u_{b}=\left(\frac{4 n}{1+3 n}\right) u_{o}
$$

And modified Prandtl number is given by [31]:

$$
P r_{b}^{*}=\frac{C p}{k_{b}} m\left(\frac{u_{b}}{D_{h}}\right)^{n-1}
$$

The Graetz number is defined by:

$$
\mathrm{Gz}=\frac{\dot{m}_{b} C p_{b}}{k_{b} L}
$$

The Péclet number is given by:

$$
P e_{b}=\frac{\rho_{b} c p_{b} u_{b} D_{h}}{k_{b}}
$$

\subsection{Coolant Calculations}

Using (Eq.2) to find the convection heat flux of nanofluid can be represented by:

$$
q_{n f}=\frac{Q_{n f}}{A_{i}}
$$

$\mathrm{A}_{\mathrm{i}}=\pi \mathrm{d}_{\mathrm{o}} \mathrm{L}$

The nanofluid local heat transfer coefficient can be obtained as:

$$
\bar{h}_{b}=\frac{q_{n f}}{\pi d_{o} L\left(t_{b}-t_{w x}\right)}
$$

And the nanofluid local Nusselt number can be obtained as:

$$
\bar{N} u_{n f}=\frac{\bar{h}_{n f} D_{h}}{k_{n f}}
$$

Where hydraulic diameter of inner pipe calculate as: $\mathrm{Dh}=\mathrm{di}$

For Newtonian nanofluid, the Reynolds number is defined as:

$$
\operatorname{Re}_{n f}=\frac{\rho_{n f} u_{n f} D_{h}}{\mu_{n f}}
$$

The Darcy friction factor (f) of the nanofluid flowing through inner pipe is defined as:

$$
f_{w}=\frac{2 D_{h} \Delta P_{w}}{L \rho u_{w}^{2}}
$$

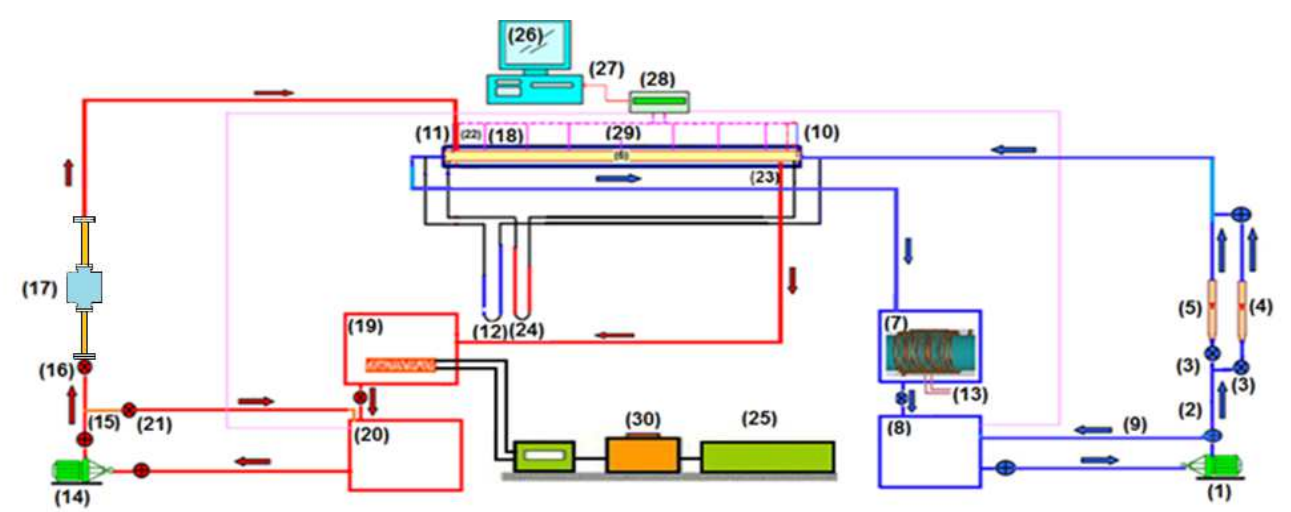

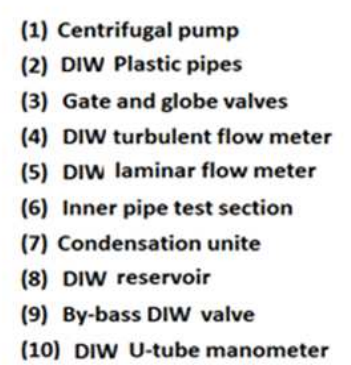

(1) Centrifugal pump

(2) DIW Plastic pipes

(3) Gate and globe valves

(5) DIw laminar flow meter

(6) Inner pipe test section

(7) Condensation unite

(9) By-bass DIW valve

(10) DIW U-tube manometer
(11) DIW inlet thermpcopule

(12) DIW outlet thermpcopule

(13) Electric power to pump and cooling unit

(14) BMF centrifugal pump

(15) BMF Plastic pipes

(16) Globe valves

(17) BMF laminar flow meter

(18) Annular passage test section

(19) Heating unite

(20) BMF collection tank.
(21) By-bass BMF side

(22) BMF inlet thermocouple

(23) BMF outlet thermocouple

(24) BMF U-tube manometer

(25) Electric power of heater and BMF pump

(26) Laptop collecting data unit

(27) Two multi ported pin

(28) LabJack U6 data acquisition unit

(29) Type-T thermocouples

(30) Electric Variac

Figure 1. Schematic diagram of experimental rig used in present study. 


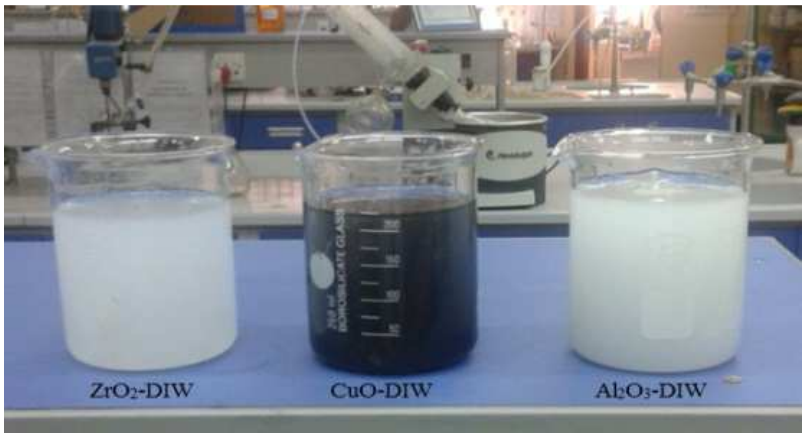

Figure 2. Samples of $\left(\mathrm{ZrO}_{2}-\mathrm{DIW}, \mathrm{CuO}-\mathrm{DIW}, \gamma \mathrm{Al}_{2} \mathrm{O}_{3}\right.$-DIW) nanofluids stability with time at $\phi=0.2 \%$.

\section{Results and Discussion}

The experimental conditions used in this study are:

(a) The flow rates of the laminar hot Newtonian BMF are (2, 3, 4 and 5 liter/min)

(b) The flow rates of the laminar hot non-Newtonian BMF are $(2.5,3.5,4.5$ and 5.5 liter $/ \mathrm{min})$

(c) The temperatures of the hot BMF are $(38,40$ and

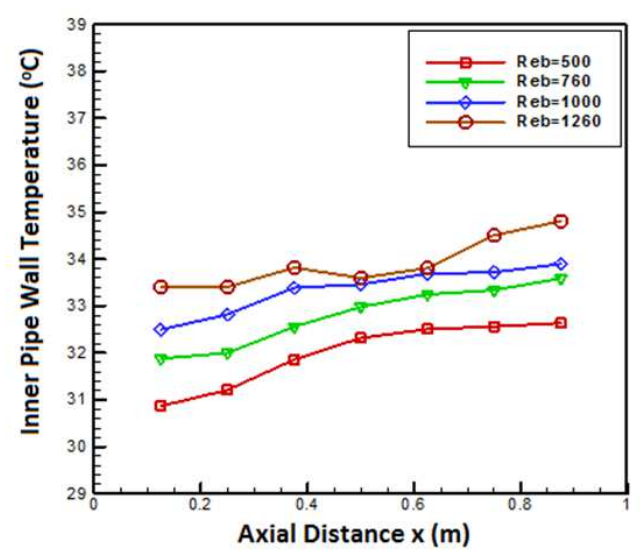

(a) BMF2 $\left.42^{\circ} \mathrm{C}\right)$

(d) The flow rates of the laminar cold nanofluid are $(0.3$, $0.5,0.7$ and 0.8 liter/min)

(e) The flow rates of the turbulent cold nanofluid are $(2,3$, 4 and 5 liter/min)

(f) The temperatures of the cold nanofluid are $(18,20$ and $\left.22^{\circ} \mathrm{C}\right)$.

\subsection{Temperature Distribution}

The variation curves of inner pipe wall temperatures $\left(\mathrm{T}_{\mathrm{wx}}\right)$ have the general shape plotted in (Figure. 3a, b) in the case of using the nanofluid to cooling (BMF2 and BMF6) under the laminar condition. It shows that the $\left(\mathrm{T}_{\mathrm{wx}}\right)$ increases gradually from (pipe inlet $x=0.0 \mathrm{~m}$ ), along the inner pipe until to attains a maximum value at (pipe exit $x=1.0 \mathrm{~m}$ ). (Figure. 4) shows the variation of $\left(\mathrm{T}_{\mathrm{wx}}\right)$ for nanofluid laminar and turbulent flow to cool the Bovine blood $(\mathrm{H}=35 \%)$ and BMF6 models it shows that the using BMF6 gives the nearest values of $\left(\mathrm{T}_{\mathrm{wx}}\right)$. Due to approach between the non-Newtonian fluid behavior BMF6 and Bovine blood in the rheological behavior index (n) of the two fluids.

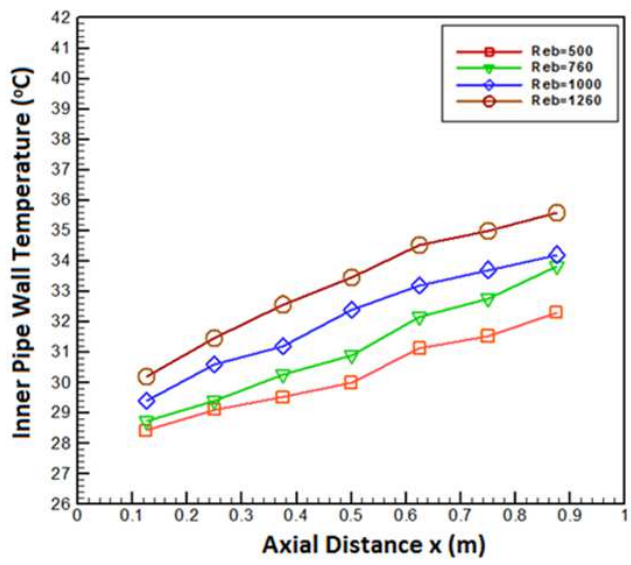

(b) BMF6

Figure 3. Effect of annular Reynolds number on the inner pipe wall temperatures $\left(T_{w x}\right)$ for laminar DIW for cooling (BMF2 and $\left.B M F 6\right)\left(T_{n f i n}=20^{\circ} \mathrm{C}\right.$, $T_{b i n}=40^{\circ} \mathrm{C}$ and $\operatorname{Re}_{n f i n}=830$ ).

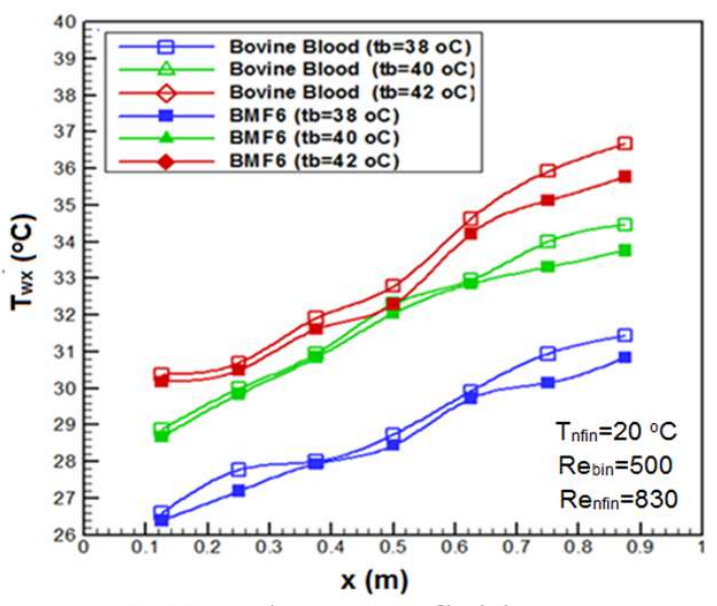

(a) Laminar nanofluid

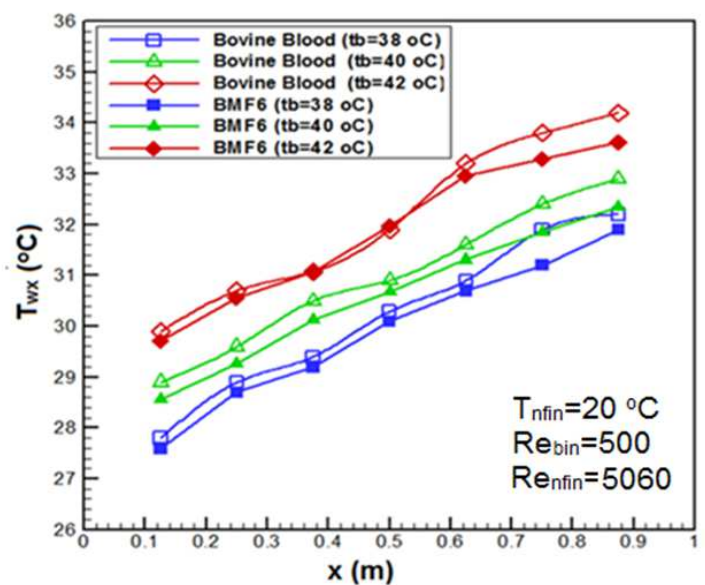

(b) Turbulent nanofluid

Figure 4. BMF inlet temperatures on inner pipe wall temperatures $\left(T_{w x}\right)$ for cooling the Bovine blood and BMF6. 
(Figure. 5) illustrates the effect of nanofluids types and concentrations on the experimental inner pipe wall temperature $\left(\mathrm{T}_{\mathrm{wx}}\right)$ for cooling the $(\mathrm{BMF} 2)$ for various nanofluid inlet temperatures. Show that the temperatures in the case of using (DIW, $\mathrm{Al}_{2} \mathrm{O}_{3}, \mathrm{CuO}$ and $\mathrm{ZrO}_{2}-\mathrm{DIW}$ ) at ( $\phi=0.02$ vol. \%) and can be show a good enhancement in decreasing $\left(\mathrm{T}_{\mathrm{wx}}\right)$. where (Figure. 5. a) gives decreasing of (8.1\%) when using $\mathrm{Al}_{2} \mathrm{O}_{3}$, with using (Figure. 5c) $\mathrm{CuO}$ gives

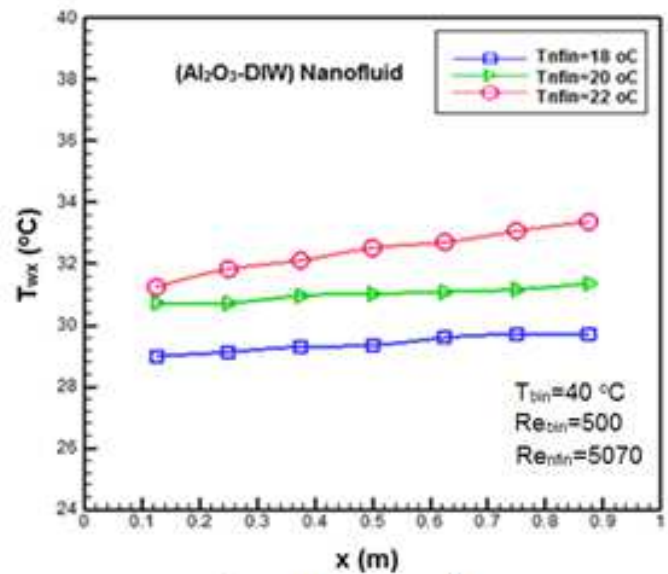

(a) $\varnothing=0.02$ vol. $\%$

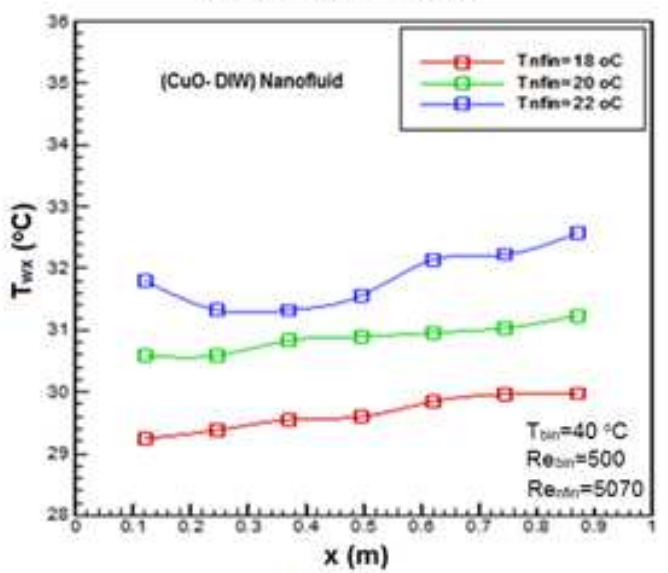

(c) $\varnothing=0.02$ vol. $\%$

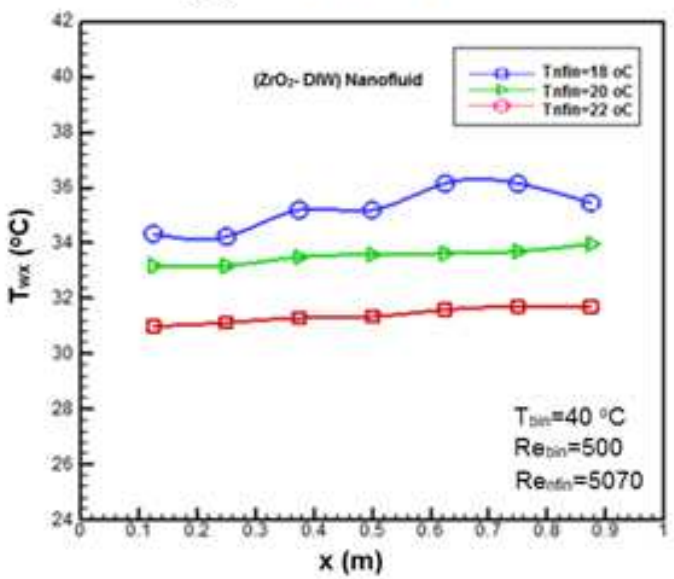

(e) $\varnothing=0.02$ vol. $\%$
(7.4\%) and gives decreasing about (4.8\%) when using $\mathrm{ZrO}_{2}$ (Figure. 5e) instead of DIW. When increasing the concentration from $(\phi=0.02$ vol. $\%) \mathrm{Al}_{2} \mathrm{O}_{3}$ (Figure. 5a) to $\left(\varnothing=0.2\right.$ vol. \%) $\mathrm{Al}_{2} \mathrm{O}_{3}$ (Figure. 5b) shows that the $\left(\mathrm{T}_{\mathrm{wx}}\right)$ increasing about $(13.5 \%)$ at $\left(\mathrm{t}_{\mathrm{nf}}=18^{\circ} \mathrm{C}\right)$, this indicating the ability of $\mathrm{Al}_{2} \mathrm{O}_{3}$-DIW fluid to extraction the heat from the inner wall and cooling the surface of the inner pipe by increasing the nanoparticles concentration.

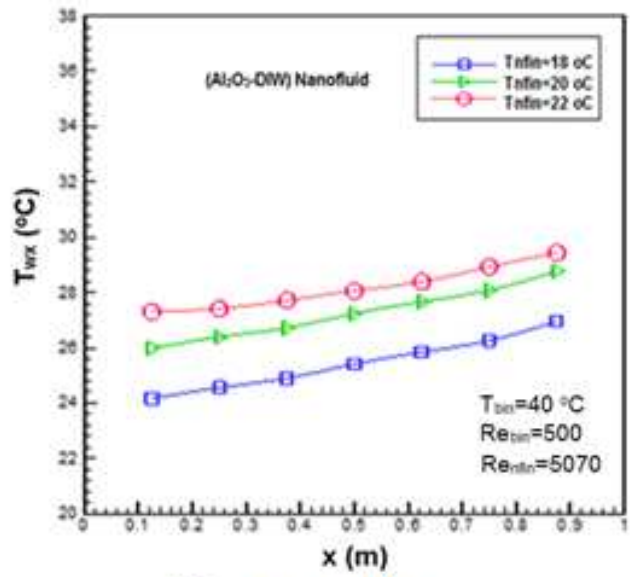

(b) $\varnothing=0.2$ vol. $\%$

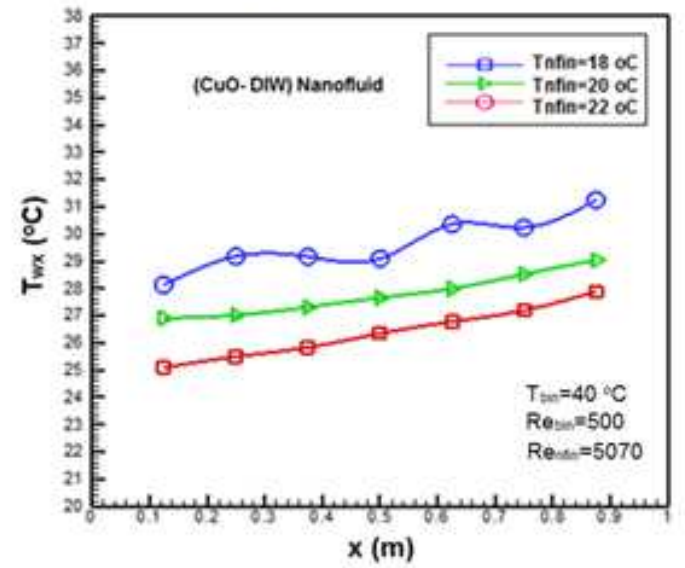

(d) $\varnothing=0.2$ vol. $\%$

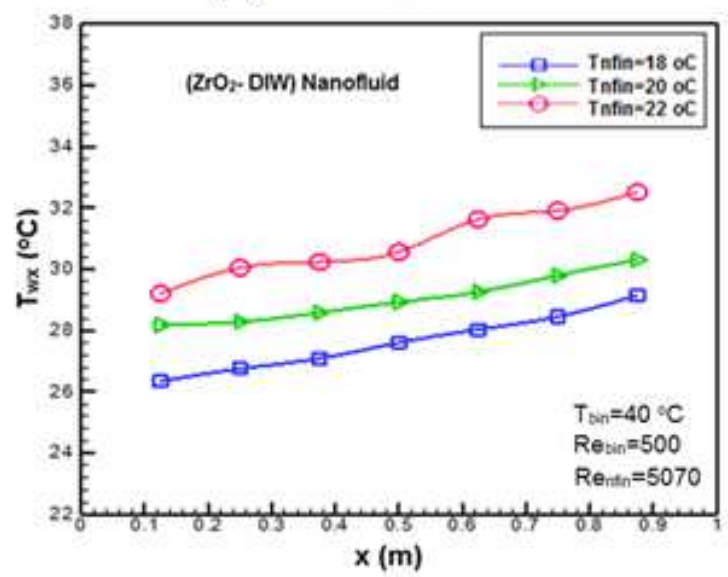

(f) $\varnothing=0.2$ vol. $\%$

Figure 5. Effect of nanofluids types and nanoparticles concentration on the inner pipe wall temperature $\left(T_{w x}\right)$ to cooling (BMF2) for various nanofluid inlet temperatures. 
The effect of the inner Reynolds number (nanofluid) can be found in (Figure. $6 \mathrm{a}, \mathrm{b}$ ) for the case of using $\left(\mathrm{Al}_{2} \mathrm{O}_{3}\right.$-DIW) at concentration of the nanoparticles $(\phi=0.2)$. It shows that the Reynolds number will be changed from case to another according to the types of the nanofluid and according to the concentration of the nanoparticles $(\phi)$ due to the differences in the thermo phsical properties for various concentrations.

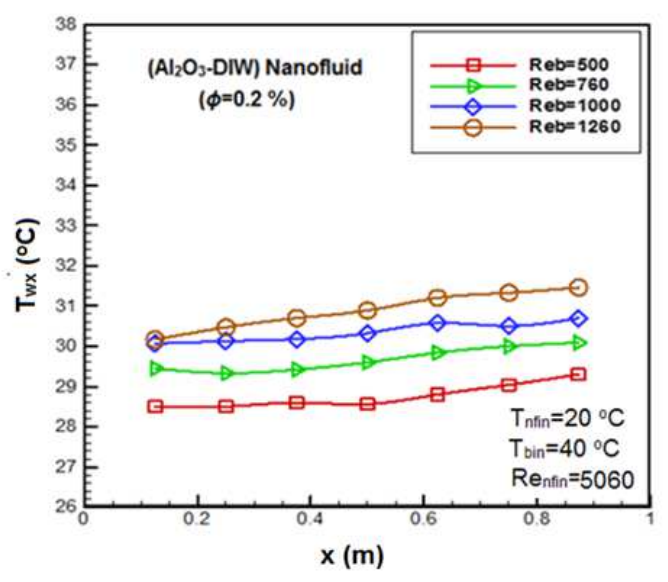

(a) BMF2

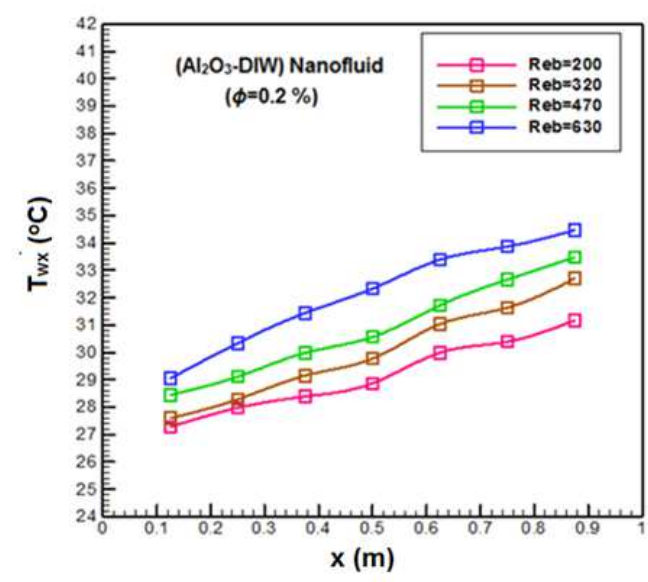

(b) BMF6

Figure 6. Effect of nanofluids types on the inner pipe wall temperature $\left(T_{w x}\right)$ to cooling the (BMF2 and BMF6).

Comparison of using DIW and $\left(\mathrm{Al}_{2} \mathrm{O}_{3}\right.$-DIW) type on experimental $\left(\mathrm{T}_{\mathrm{wx}}\right)$, (Figure. 7) shows that $\left(\mathrm{T}_{\mathrm{wx}}\right)$ decreases

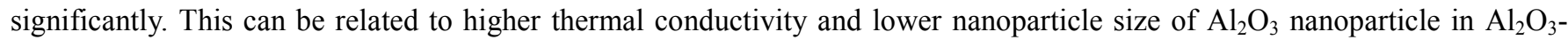
DIW nanofluid. This leads to high Brownian motion and increasing the conductance heat transfer between the inner pipe and the nanoparticles.

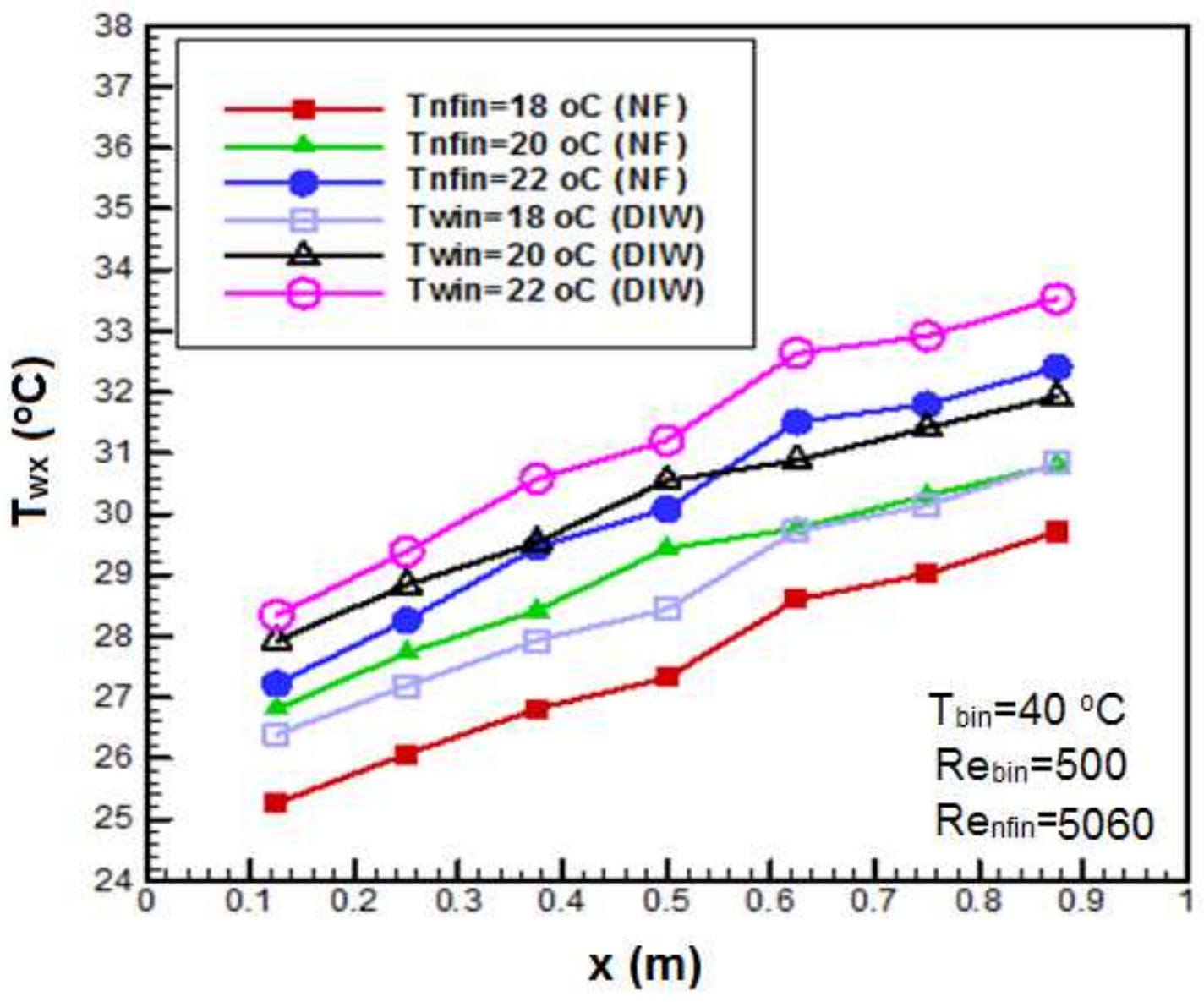

Figure 7. Effect of $\left(\mathrm{Al}_{2} \mathrm{O}_{3}-\mathrm{DIW}-\varnothing=0.2 \mathrm{vol}\right.$. \%) type on the inner pipe wall temperature $\left(T_{w x}\right)$ to cooling the (BMF2). 
(Figure. 8 a, b) shows the effect of nanoparticles concentration in the case of using types of coolants (DIW, $\mathrm{Al}_{2} \mathrm{O}_{3}, \mathrm{CuO}$ and $\left.\mathrm{ZrO}_{2}\right)$ on the experimental $\left(\mathrm{T}_{\mathrm{wx}}\right)$ to cool the (BMF2). Zero concentration of the nanoparticles $(\phi=0.0)$ for (DIW), clearly show that increasing the concentration of the nanoparticles $(\phi)$ in the nanofluid decrease the $\left(\mathrm{T}_{\mathrm{wx}}\right)$, in $\mathrm{Al}_{2} \mathrm{O}_{3}$ (Figure. 8 a). Increasing the concentration of the

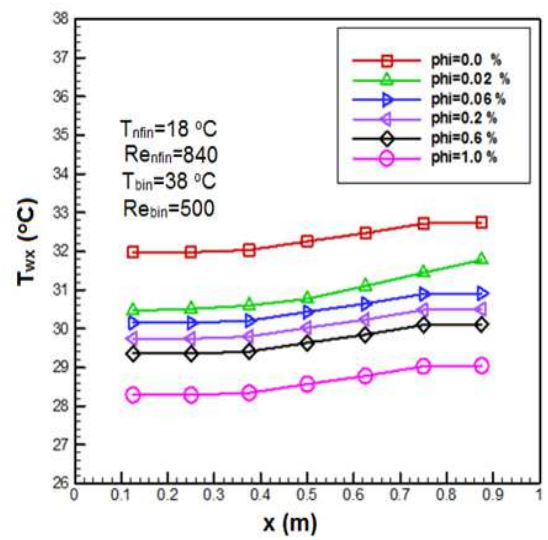

(a) $\mathrm{Al}_{2} \mathrm{O}_{3}$-DIW nanoparticles $\phi$ (from 0.0 to 1.0 vol. $\%$ ) causes a decrease in the $\left(\mathrm{T}_{\mathrm{wx}}\right)$ by $(8.1 \%)$. due to increasing of the thermal conductivity of the base fluid DIW for all types of nanofluid. (Figure. 8b) compares between coolant types (DIW, $\mathrm{Al}_{2} \mathrm{O}_{3}$, $\mathrm{CuO}$ and $\mathrm{ZrO}_{2}$ ). It shows that using $\mathrm{Al}_{2} \mathrm{O}_{3}$ gives the lowest $\left(\mathrm{T}_{\mathrm{wx}}\right)$ and DIW gives the highest with decreasing percent of $(12.1 \%)$.

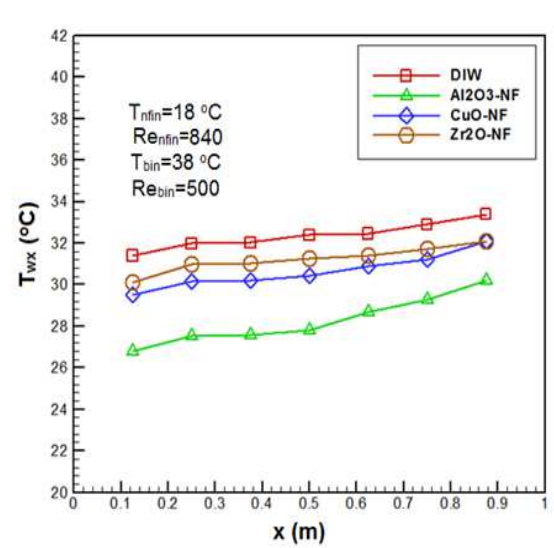

(d) All Coolants

Figure 8. Effect of nanoparticles concentration of coolant types on the inner pipe wall temperature $\left(T_{w x}\right)$, to cooling the (BMF2).

\subsection{Convective Heat Transfer}

Effect of using Bovine blood compared with BMF6 suggested in this study on the annular Nusselt number $\left(\mathrm{Nu}_{\mathrm{b}}\right)$ with Greatz number at the same experimental conditions showed in (Figure. 9). The results show the Bovine blood gives decreasing in $\left(\mathrm{Nu}_{\mathrm{b}}\right)$ by $(19.4 \%)$ compared with non-Newtonian BMF6 but gives maximum increasing of $\left(\mathrm{Nu}_{\mathrm{b}}\right)$ if compared with $\mathrm{Newtonian}$ BMF2 by $(14.6 \%)$ at $(\mathrm{Gz}=500)$.

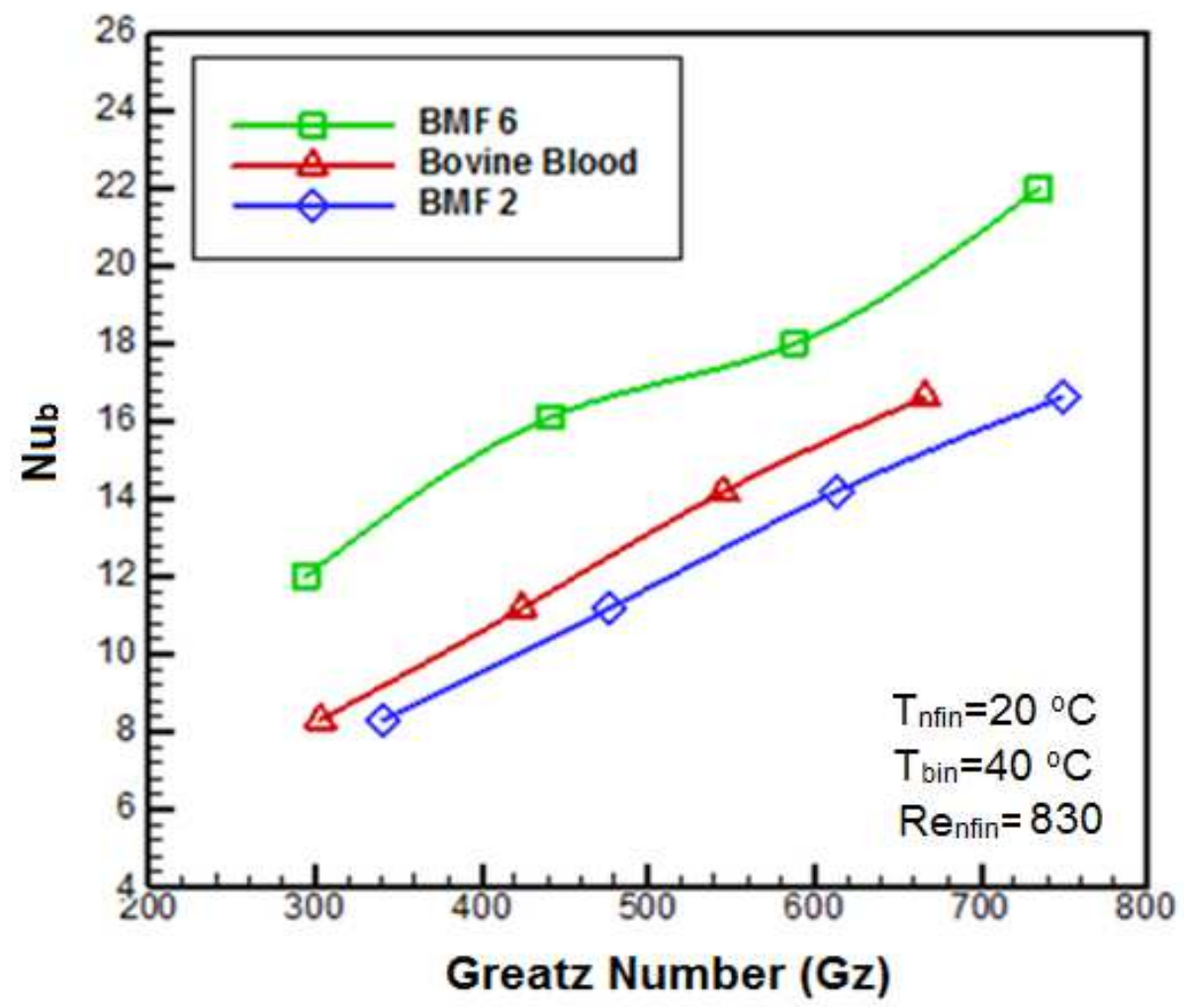

Figure 9. Effect of using Bovine blood and BMF6 types on variation of annular Nusselt number, with Greatz number. 
The effect of the annular Reynolds number of the BMF2 and BMF6 on the annular Nusselt number $\left(\mathrm{Nu}_{\mathrm{b}}\right)$ is illustrated in (Figure. $10 \mathrm{a}, \mathrm{b})$ for laminar DIW. The $\left(\mathrm{Nu}_{\mathrm{b}}\right)$ began at high value at (pipe exit $\mathrm{x}=1.0 \mathrm{~m}$ ) and dropped gradually forward to the (pipe inlet $\mathrm{x}=0.0 \mathrm{~m}$ ) due to counter flow. And the overall behavior of $\left(\mathrm{Nu}_{\mathrm{b}}\right)$ seems as straight line for the folly developing region in the test section. This shows that the annular Reynolds numbers different according to the BMF

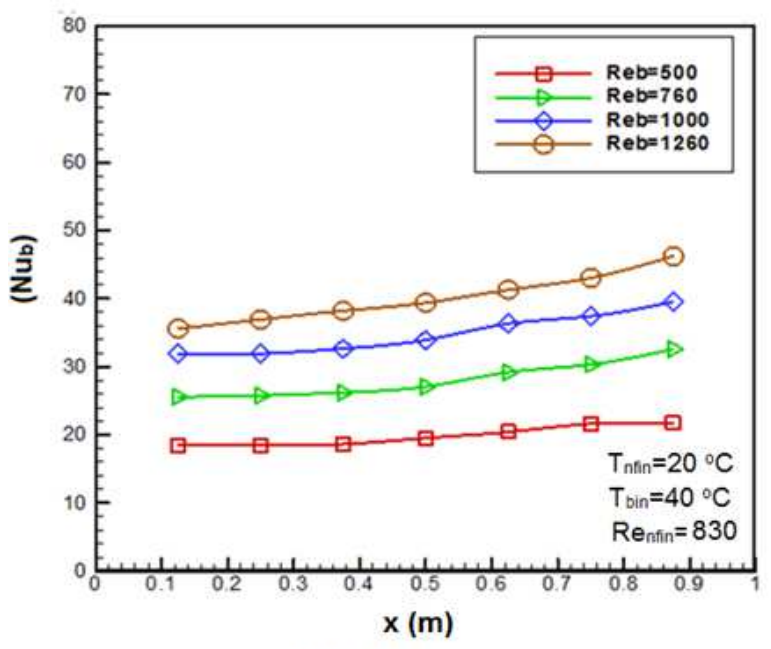

(a) BMF2 models type because of the difference in the thermophysical properties and rheological behavior especially on the flow behavior index (n) between these fluids. It is observed that the $\left(\mathrm{Nu}_{\mathrm{b}}\right)$ increases with annular Reynolds number. The Newtonian type (BMF1) in (Figure. 10a) gives maximum increasing of $(51 \%)$ when increasing the $\mathrm{Re}_{\mathrm{b}}$ from 500 to 1260.

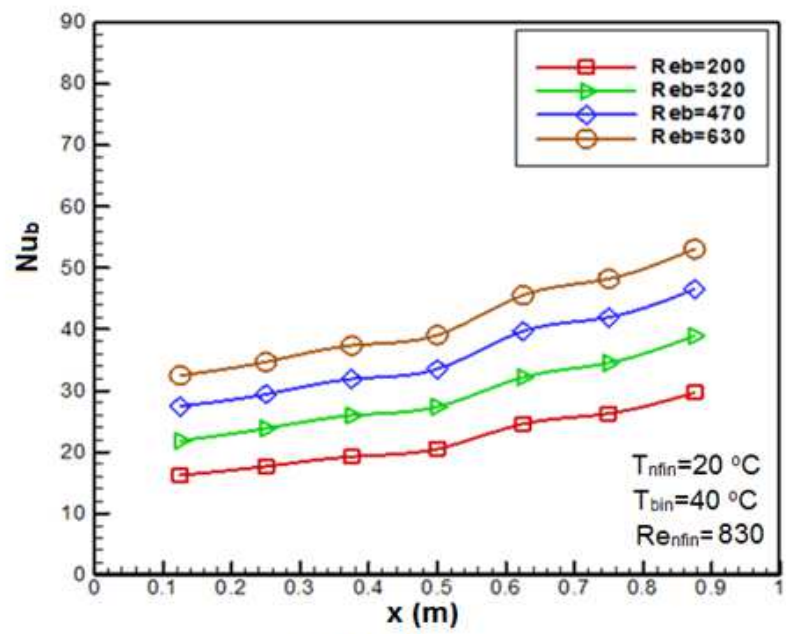

(b) BMF6

Figure 10. Effect of BMF types on the variation of annular Nusselt number, at various annular Reynolds number.

The types of BMF flow in the annulus, are given in (Figure. $11 \mathrm{a}, \mathrm{b}$ ) for laminar and turbulent DIW flow conditions ( $R$ ew $=830$ and 5070) with various Greatz number $(\mathrm{Gz}=\mathrm{RePr})$. The results show that the (Nub) increases by (51.6\%) with increasing Gz from 500 to 1260 for using BMF1, and by (46.2\%) when using BMF6 but the BMF4 gives the high (Nub).

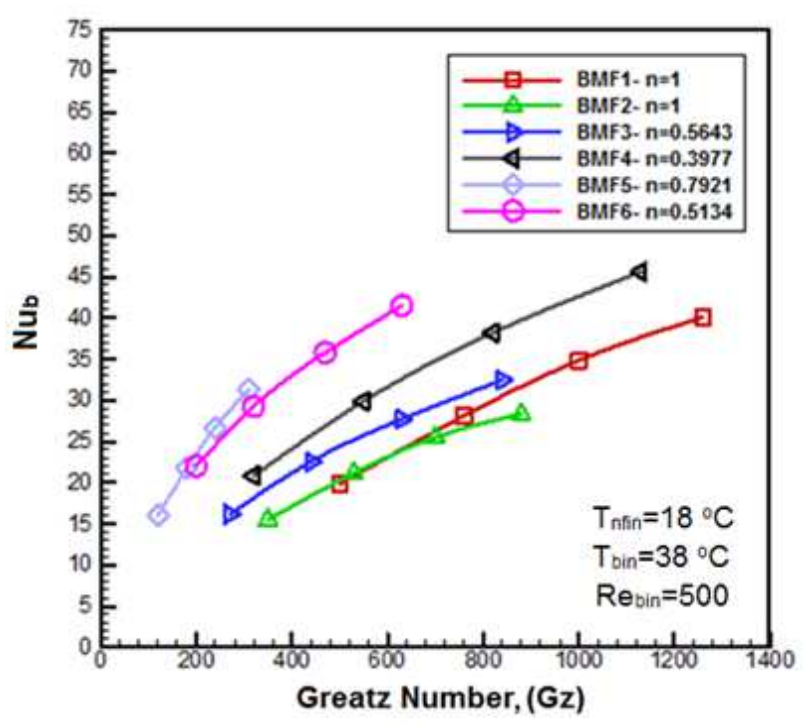

(a) $\operatorname{Re}_{\mathrm{w}}=830$

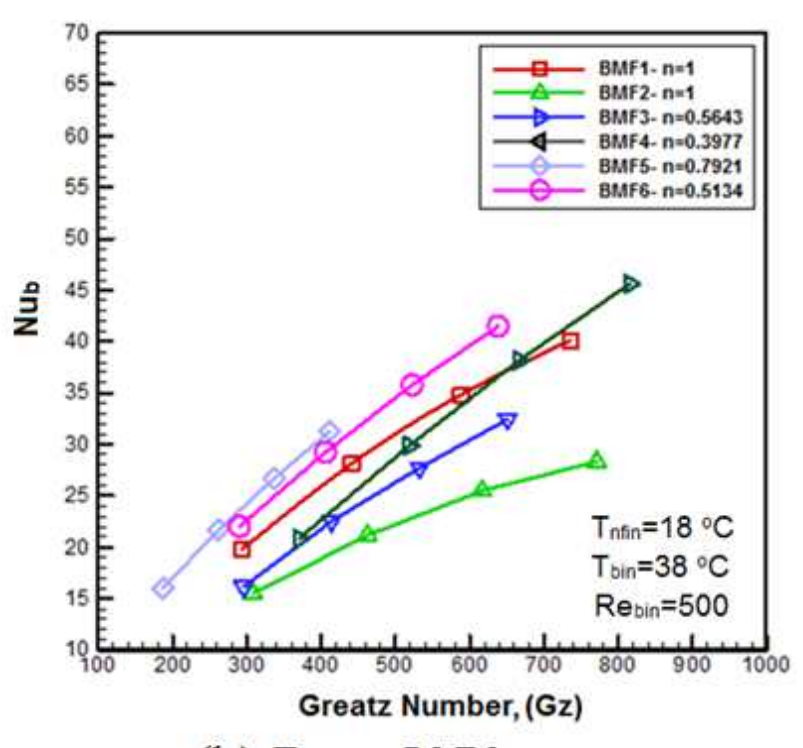

(b) $\mathrm{Re}_{\mathrm{w}}=5070$

Figure 11. Effect of flow indices (n) and type of BMF on the annular Nusselt number $\left(N u_{b}\right)$.

(Figure. $12 \mathrm{a}, \mathrm{b})$ presents the effect of inner nanofluid Reynolds number in the condition of turbulent flow, using $\left(\mathrm{Al}_{2} \mathrm{O}_{3}\right.$ DIW) at $(\phi=0.2 \%)$ as a coolant to cooling (BMF2 and BMF6). It is noted that the local inner Nusselt number $\left(\mathrm{Nu}_{\mathrm{nf}}\right)$ increased with increasing nanofluid Reynolds number by (82.4\%) if $\mathrm{Re}_{\mathrm{w}}$ increased from (5070 to 12670). 


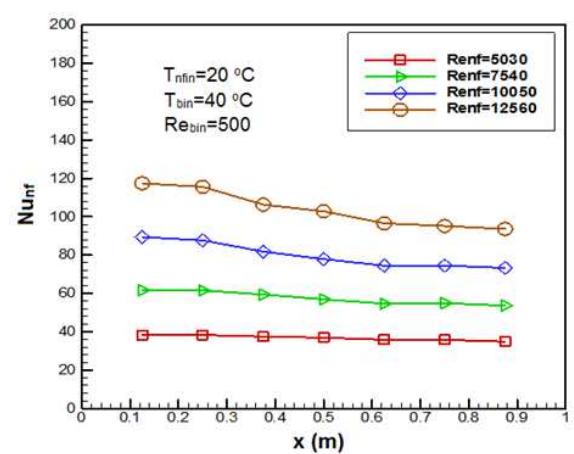

(c) BMF2

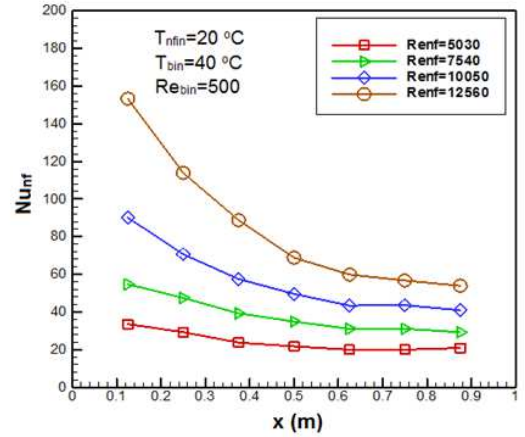

(d) BMF6

Figure 12. Effect of Inner Reynolds number on the inner Nusselt number, to cool a (BMF2 and BMF6).

The effect of increasing concentration $(\phi)$ on average inner Nusselt number with the inner Reynolds number shows in (Figure. $13 \mathrm{a}, \mathrm{b}$ ). The laminar and turbulent flow conditions for DIW and $\left(\mathrm{Al}_{2} \mathrm{O}_{3}\right.$-DIW) to cool a (BMF2). It shows that the average inner Nusselt number increased with inner Reynolds number. And $(\mathrm{Nu})$ increases with increasing the

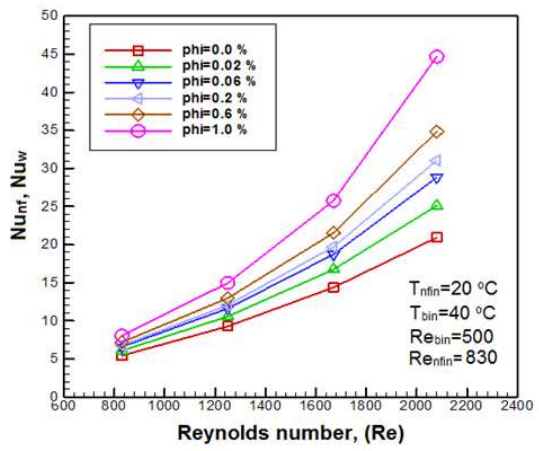

(a) Laminar concentrations by $(53.3 \%)$ when increased the concentration from ( $\phi=0.0$ to 1.0 vol. $\%)$ at $R e=1640$ in the laminar flow, and increased by $(71.1 \%)$ in the turbulent flow at $\mathrm{Re}=10050$. This is due to the enhancement in the thermal conductivity produced by adding the solid nanoparticles to the DIW.

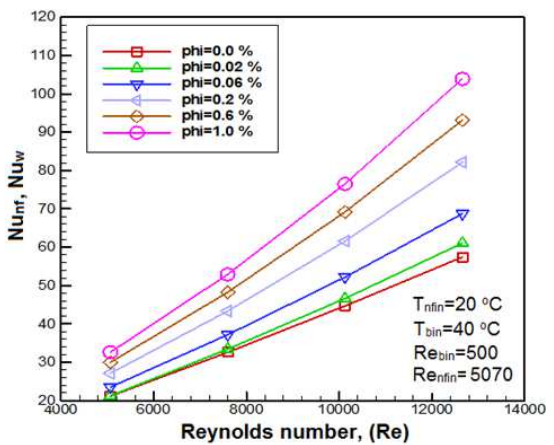

(b) Turbulent

Figure 13. Effect of the nanoparticle concentration on the experimental variation of inner Nusselt number with the inner Reynolds number, of DIW and $\left(\mathrm{Al}_{2} \mathrm{O}_{3}-\mathrm{DIW}\right)$ to cooling a $(\mathrm{BMF} 2)$.

\subsection{Friction Factor}

Pressure drop results for the BMF models are presented in (Figure. $14 \mathrm{a}, \mathrm{b}$ ). It shows the effect of the BMF types and flow index (n) of Newtonian and non-Newtonian (BMF) on the annular friction factor. It basically shows that the four nonNewtonian fluid BMF models have the highest values of friction factor as compared with the two Newtonian fluids BMF models due to increasing the fluid viscosity and rheological properties. (Figure. 14 a) shows that the $\left(f_{b}\right)$ increases by $(34.6 \%)$ at $\mathrm{Re}=360$ between the BMF1 and BMF2.

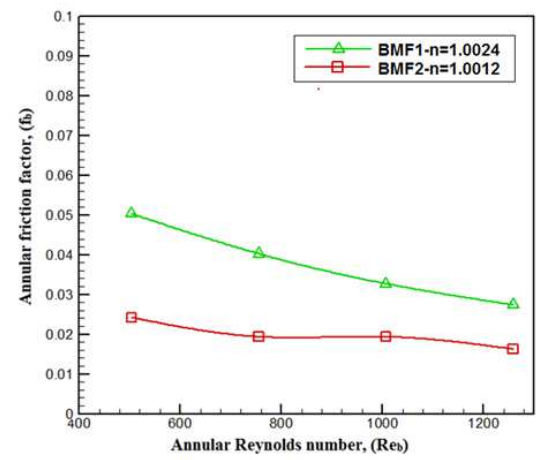

(a) Newtonian BMF models

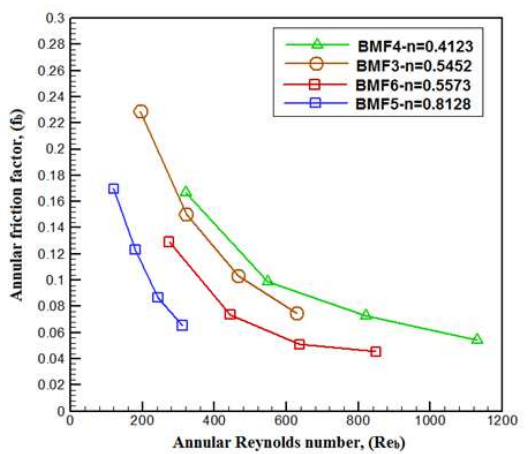

(b) non-Newtonian BMF models

Figure 14. Effect of the BMF types and flow index (n) of Newtonian BMF on the annular friction factor with the annular Greatz number. 
(Figure. 15) shows the effect of using Bovine blood and BMF6 on the experimental annular friction factor with the annular Greatz number. It shows that the real bovine blood gives a maximum annular friction factor by (21.3\%) compared with BMF6.

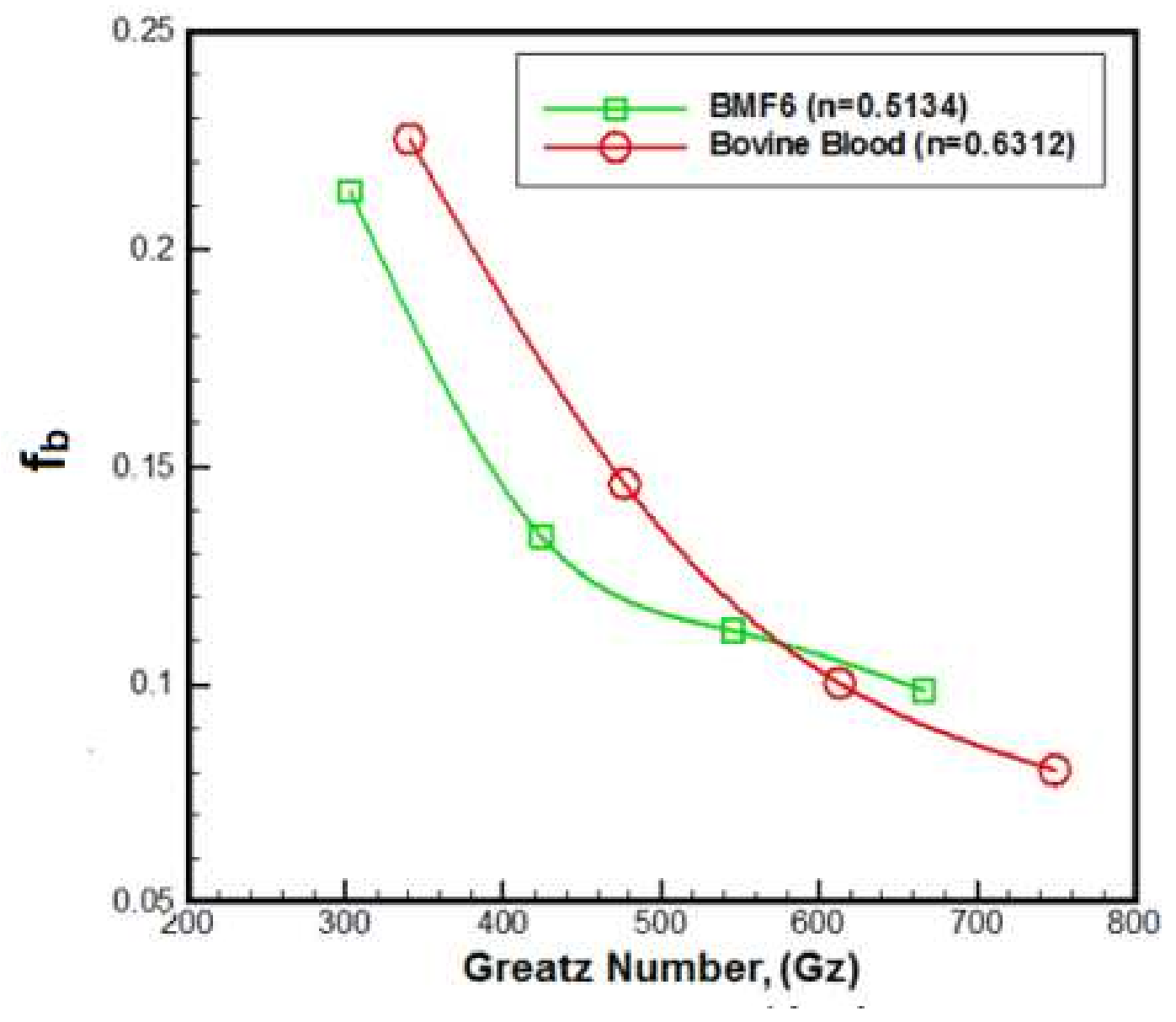

Figure 15. Effect of the Bovine blood and BMF6 on the annular friction factor.

The behavior of friction factor for the types of coolant at laminar and turbulent flow in (Figure. $16 \mathrm{a}, \mathrm{b}$ ) shows that the inner friction factor decreases with increasing Reynolds number for all types. But when using $\left(\mathrm{Al}_{2} \mathrm{O}_{3}\right.$-DIW) gives the highest friction factor by $(40.2 \%)$ for laminar condition at

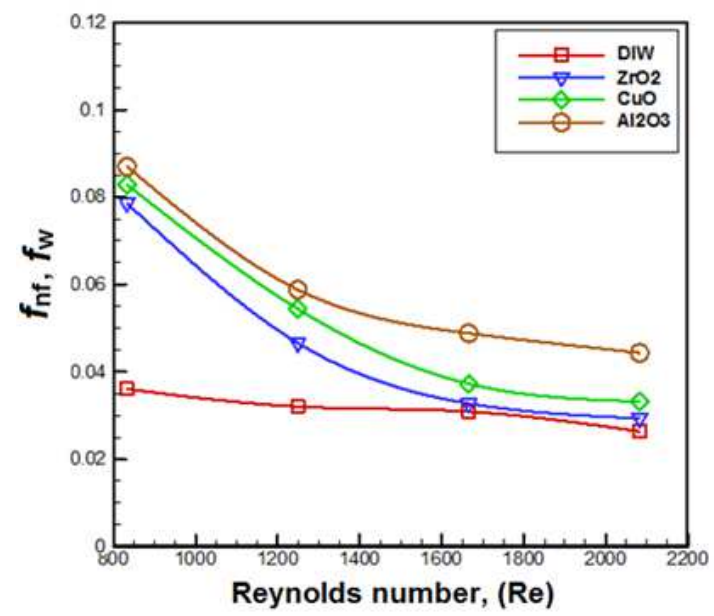

(a) Laminar
$\mathrm{Re}_{\mathrm{nf}}=1630$ due to the smallest nanoparticles diameter of (20 $\mathrm{nm}$ ) lead to increasing the nanofluid viscosity and then increased pressure drop. But $\left(\mathrm{Al}_{2} \mathrm{O}_{3}\right.$-DIW) shows the highest values for turbulent flow condition by $(36.6 \%)$ at $(\mathrm{Re}=10080)$ as compared with the DIW.

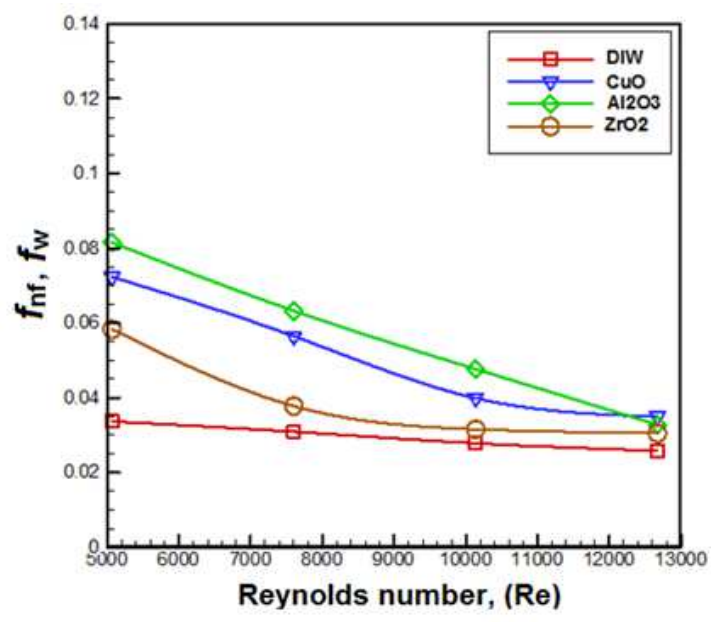

(b) Turbulent

Figure 16. Effect of using three type of Nanofluid at $(\phi=0.2)$ on the inner friction factor. 
Effect of the concentration of $\left(\mathrm{Al}_{2} \mathrm{O}_{3}\right.$ - DIW) on friction factor for laminar and turbulent flows presented in (Figure. $17 \mathrm{a}, \mathrm{b})$. The inner friction factor for all nanofluids increases with increasing the nanoparticles concentrations by $(33.2 \%)$

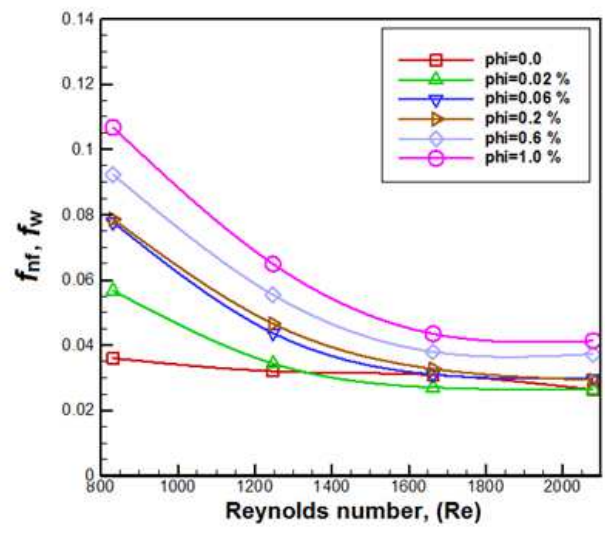

(a) Laminar when $\phi$ increased (from 0.0 to 1.0 vol. \%) for laminar $\mathrm{Re}_{\mathrm{w}}=1630$ and by about (36.3\%) for turbulent $\mathrm{Re}_{\mathrm{w}}=10050$. The rise in friction factor is due to rise in viscosity of the nanofluids when the nanoparticles are adding to the DIW.

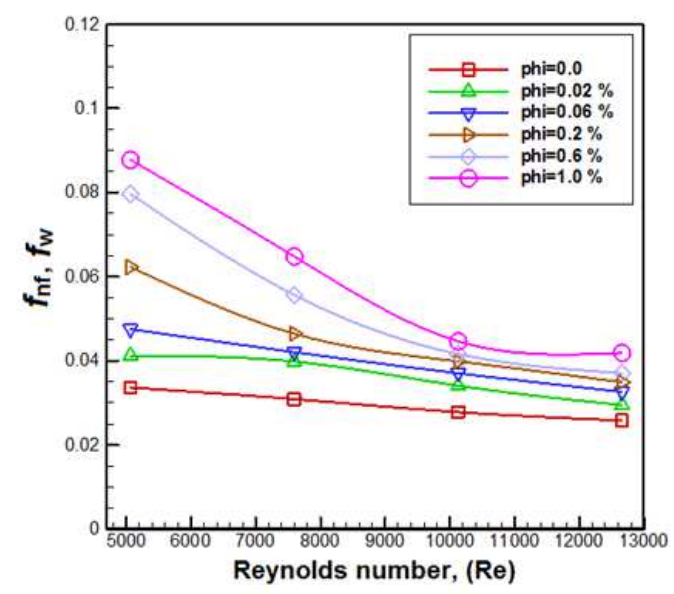

(b) Turbulent

Figure 17. Effect of the nanoparticle concentration of $\left(\mathrm{Al}_{2} \mathrm{O}_{3}-\mathrm{DIW}\right)$ on the inner friction factor.

\subsection{Performance Evaluation Criterion (PEC)}

Performance evaluation criterion: is defined as the ratio of heat transferred to the required pumping power in the BMF section [32]:

$$
P E C=\frac{m c p\left(T_{\text {out }}-T_{\text {in }}\right)}{v \Delta P}
$$

(Figure. 18 a, b) shows the PEC was decreased with increasing inner Reynolds number due to increasing pressure drop across the inner pipe for all types of nanofluid at

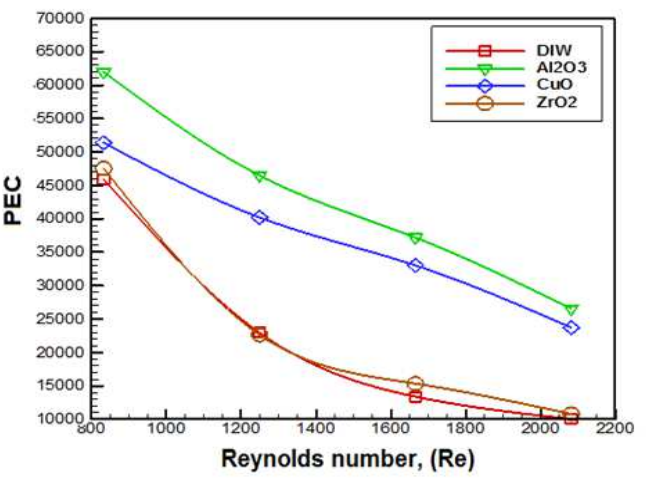

(a) Laminar concentration ( $\phi=0.2$ vol. \%). The DIW and $\mathrm{ZrO}_{2}$-DIW give low values and the $\mathrm{CuO}-\mathrm{DIW}$ gives an increasing PEC by (52\%) and $\mathrm{Al}_{2} \mathrm{O}_{3}$-DIW gives increasing by $(57 \%)$ for laminar condition of $(\mathrm{Re}=1200)$ than the using DIW. But for the case of turbulent flow, it can be observed that the value of PEC is very low compared with the laminar condition due to the higher value of pressure drop. The $\mathrm{ZrO}_{2}$-DIW gives an increasing in the PEC by (11\%), for CuO-DIW by (34\%) and for $\mathrm{Al}_{2} \mathrm{O}_{3}$-DIW about $(56 \%)$ at turbulent condition of $(\mathrm{Re}=7500)$.

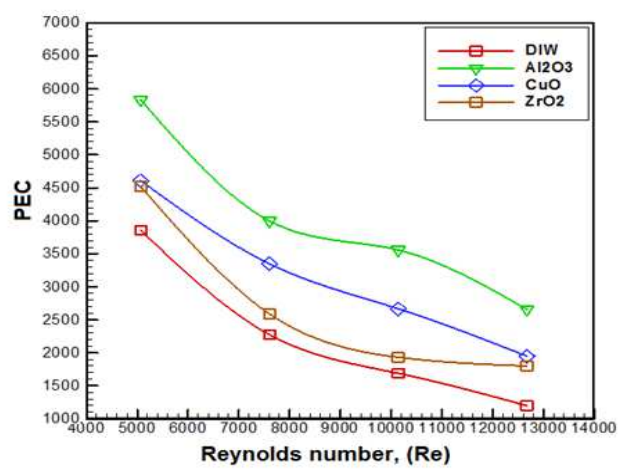

(b) Turbulent

Figure 18. Effect nanofluid types at $(\varnothing=0.2$ vol. \%) and DIW on (PEC) with the inner Reynolds number.

\subsection{Validation Results with Proposed Correlations}

To compared the experimental annular Nusselt number (Nub) for Newtonian and non-Newtonian BMF using (Figure. 19a, b) as comparison the experimental Results of (Nub) flow with the Newtonian and non-Newtonian Leveque Eq. [33] general equation (Eq. 23), and obtained on the acceptable agreements with deviation about (15.4\%) for the
Newtonian BMF2 and about (9.7\%) for the non-Newtonian BMF6.

$$
\begin{aligned}
& N u_{b}=1.75 G z^{1 / 3} \\
& N u_{b}=1.75 \Delta^{1 / 3} G z^{1 / 3}
\end{aligned}
$$




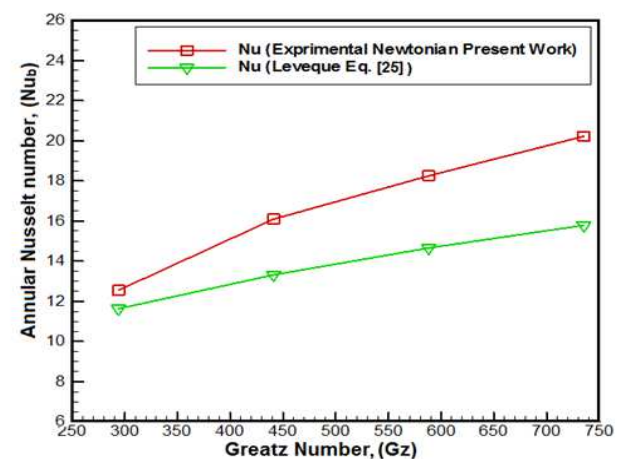

(a) BMF2

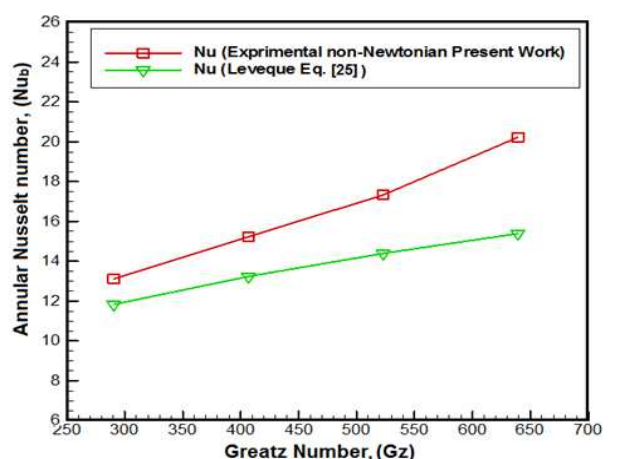

(b) BMF6

Figure 19. Comparison the experimental results of annular Nusslte number for Newtonian and non-Newtonian (BMF) flow with the Leveque [30] equation.

In general, Nusselt numbers and friction factor of the working fluids related with parameters listed in (Table.3).

Table 3. General form of the correlations.

\begin{tabular}{|c|c|c|c|}
\hline \multirow{4}{*}{ Nanofluid } & \multirow{2}{*}{ Laminar } & $\mathrm{Nu}$ & $N u_{n f}=f\left((\operatorname{Re} \operatorname{Pr} D / L)_{n f}^{a 1}, \phi^{c 1}\right)$ \\
\hline & & $f$ & $f_{n f}=f\left(\operatorname{Re}_{n f}^{a 2}, \phi^{c 2}\right)$ \\
\hline & \multirow{2}{*}{ Turbulent } & $\mathrm{Nu}$ & $N u_{n f}=f\left(\operatorname{Re}_{n f}^{a 3}, P_{n f}^{b 3}, \phi^{c 3}\right)$ \\
\hline & & $f$ & $f_{n f}=f\left(\operatorname{Re}_{n f}^{a 4}, \phi^{c 4}\right)$ \\
\hline \multirow{4}{*}{ BMF } & \multirow{2}{*}{ Newtonian } & $\mathrm{Nu}$ & $N u_{b}=f\left(G z_{b}^{a 5}, \Delta^{c 5}\right)$ where $\Delta=1+3 \mathrm{n} / 4 \mathrm{n}$ \\
\hline & & $f$ & $f_{b}=f\left(\operatorname{Re}_{b}^{a 6}, \Delta^{c 6}\right)$ \\
\hline & \multirow{2}{*}{ non-Newtonian } & $\mathrm{Nu}$ & $N u_{b}=f\left(G z_{b}^{a 7}\right)$ \\
\hline & & $f$ & $f_{b}=f\left(\operatorname{Re}_{b}^{a 8}\right)$ \\
\hline
\end{tabular}

The equation for predicting the heat transfer performance and friction factor of DIW, $\mathrm{Al}_{2} \mathrm{O}_{3}$-DIW nanofluid and (BMF2, BMF6) was formed and is proposed in (Table. 4). The above equations are obtained by curve fitting all the experimental data for the $\left(\mathrm{A}_{12} \mathrm{O}_{3}\right.$-DIW) nanofluids. Comparisons of the experimental results with those calculated by the proposed correlation are shown in (Figure. 20). The results show good correspondence between the experimental values and the calculated values these equations, the data falls within $( \pm 22 \%)$ of the proposed equation.

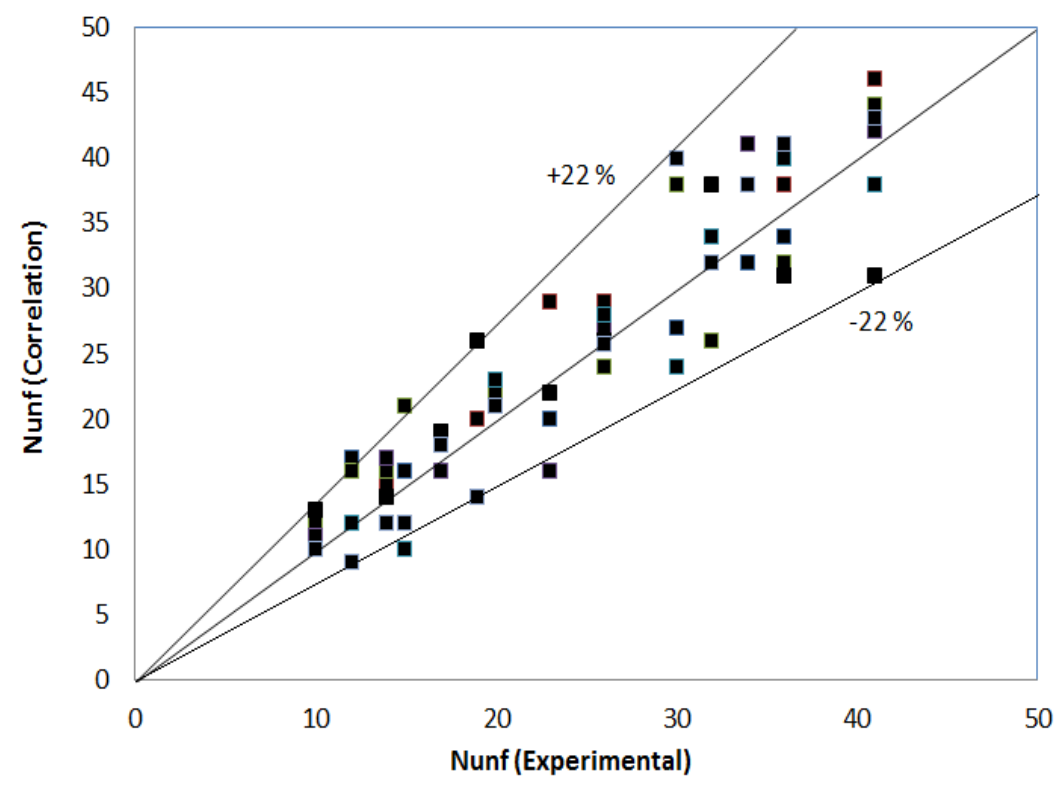

Figure 20. Plot comparing the correlation and experimental results of using $\mathrm{Al}_{2} \mathrm{O}_{3}$-DIW to cooling $\mathrm{BMF}$. 
Table 4. The equation for predicting the heat transfer and friction factor performance of $D I W, A L_{2} O_{3}$ nanofluid and Newtonian $B M F 2$, and non-Newtonian BMF6 models.

\begin{tabular}{lllll}
\hline Domain & Flow Condition & Parameter & Experimental Correlation & $\mathbf{R}^{2}$ \\
\hline & & $\mathrm{Nu}$ & $N u_{n f}=1.623\left(\frac{\operatorname{Re} \operatorname{Pr} D}{L}\right)^{0.8495}(\phi)^{0.03821}$ & 0.9965 \\
& Laminar & $\mathrm{f}$ & $f_{n f}=74.222(\mathrm{Re})^{-1}(\phi)^{0.02254}$ & 0.9852 \\
$\mathrm{Al}_{2} \mathrm{O}_{3}$-DIW & & $N u_{n f}=0.0812(\mathrm{Re})^{06895}(\mathrm{Pr})^{0.4844}(\phi)^{0.0681}$ & 0.9555 \\
& & $\mathrm{Nu}$ & $f_{n f}=0.882(\mathrm{Re})^{-0.3525}(\phi)^{0.0488}$ & 0.9552 \\
& Turbulent & $f$ & $N u_{b}=1.2332(G z)^{0.4246}$ & 0.9226 \\
& & $\mathrm{Nu}$ & $f_{b}=30.691(G z)^{-1.086}$ & 0.9435 \\
$(\mathrm{BMF})$ & $f$ & $N u_{b}=1.4221(G x)^{0.5426}(\Delta)^{0.4336}$ & 0.9662 \\
& Newtonian & $\mathrm{Nu}$ & $f_{b}=62.359(G z)^{-1.045}(\Delta)^{0.4552}$ & 0.9917 \\
\hline
\end{tabular}

\section{Conclusions}

As a result of the experimental investigation which carried out to study forced convection heat transfer for the nanofluid flows in inner pipe and BMF flows in annular space of the double pipe system, the following conclusions can be made:

a The inner pipe wall temperature is affected by the extent of the local heat transfer which decreases as (a) increasing inner coolant Reynolds number (b) decreasing BMF Reynolds number (c) decreasing coolant inlet temperatures (d) decreasing $\mathrm{BMF}$ inlet temperatures, (e) using nanofluids of $\mathrm{Al}_{2} \mathrm{O}_{3}$-DIW, CuODIW and $\mathrm{ZrO}_{2}$-DIW, (f) increasing the nanoparticles volume fraction. (g) Using high $\mathrm{Re}$ reduce the agglomeration of particles.

b The variation of BMF annular Nusslte number $\left(\mathrm{Nu}_{b}\right)$ for all cases may be affected by many factors, the $\mathrm{Nu}_{\mathrm{b}}$ increases (a) with increases $\mathrm{Re}_{\mathrm{b}}$, (b) with decreasing flow behavior index (n) as the fluids changing from Newtonian to non -Newtonian fluids and increasing the shear thinning behavior.

c The variation of inner Nusselt number $\mathrm{Nu}_{\mathrm{c}}$ increases (a) by $(22.2 \%)$ when the coolant inlet temperatures decreasing from 22 to $18^{\circ} \mathrm{C}$, (b) increases with increasing $\mathrm{Re}_{\mathrm{c}}$, (c) by using the turbulent instead of laminar flow, (d) the high $\mathrm{Nu}_{\mathrm{w}}$ obtained when using $\mathrm{Al}_{2} \mathrm{O}_{3}$, gives a maximum enhancement by $(82.4 \%)$ if $\mathrm{Re}_{\mathrm{w}}$ increased from (5070 to 12670).

$d$ The coolants inner friction factor $\left(f_{w}\right.$ and $\left.f_{n f}\right)$ decreasing with $\mathrm{Re}_{\mathrm{c}}$ increasing for all cases, but using the $\left(\mathrm{Al}_{2} \mathrm{O}_{3}-\right.$ DIW) will increase the friction factor values because its smallest nanoparticles diameter of $(20 \mathrm{~nm})$.

e The BMF inner friction factor $f_{b}$ is decreasing with $G z$ increasing for all cases, but using the non-Newtonian BMF3, BMF4, BMF5 and BMF6 Types will increase the fraction factor values because the high viscosities and different rheological properties that Newtonian fluids BMF1 and BMF2. ( $\left.f_{b}\right)$ increasing with decreasing the flow index (n).

f Bovine blood and BMF6 gives the nearest values of $\left(\mathrm{T}_{\mathrm{wx}}\right)$, but the Bovine blood gives decreasing in $\left(\mathrm{Nu}_{\mathrm{b}}\right)$ compared with BMF6 but gives maximum increasing of $\left(\mathrm{Nu}_{\mathrm{b}}\right)$ if compared with Newtonian BMF2. And bovine blood gives a maximum friction factor compared with BMF6

\section{Nomenclature}

$A$
$C_{f}$
$C p$
$D_{i}$
$D_{o}$
$D_{h}$
$d_{i}$
$d_{o}$
$f$
$H$
$h$
$k$
L
Greek letters
$\dot{\gamma}$
$\mu$

flow area, $\left(\mathrm{m}^{2}\right)$

fanning friction factor

specific heat, (J/kg. K)

internal diameter of outer pipe, (m)

external diameter of outer pipe, $(\mathrm{m})$

hydraulic diameter, $(\mathrm{m})$

internal diameter of inner pipe, $(\mathrm{m})$

external diameter of inner pipe (m)

friction factor $=$ Darcy friction factor

haematocrit, (\%)

heat transfer coefficient, $\left(\mathrm{W} / \mathrm{m}^{2} . \mathrm{K}\right)$

thermal conductivity, $(\mathrm{W} / \mathrm{m}$. K)

axial length, (m)

shear rate, $\left(\mathrm{s}^{-1}\right)$

dynamic viscosity, (Pa. s) mass flow rate, $(\mathrm{kg} / \mathrm{s})$

power-law consistency coefficient, $\left(\mathrm{Pa} . \mathrm{s}^{\mathrm{n}}\right)$

power law flow behaviour index, $(-)$

fluid static pressure, $(\mathrm{Pa})$

Heat transfer rate, (W)

volumetric flow rate, (liter/min)

Convection heat flux, $\left(\mathrm{W} / \mathrm{m}^{2}\right)$

statistical value of linear regression

local inner pipe wall temperature, $\left({ }^{\circ} \mathrm{C}\right)$

average inner pipe wall temperature, $\left({ }^{\circ} \mathrm{C}\right)$

bulk axial velocity, $(\mathrm{m} / \mathrm{s})$

pressure drop per unit length, $(\mathrm{Pa} / \mathrm{m})$

$\mathrm{x} \quad$ axial distance along pipe, $(\mathrm{m})$

Subscripts

ave average

b blood or BMF 


$\begin{array}{ll}\mu_{\text {eff }} & \text { effective viscosity, }(\mathrm{Pa} . \mathrm{s}) \\ v & \left.\text { kinematic viscosity, } \mathrm{m}^{2} / \mathrm{s}\right) \\ \tau & \text { shear stress, }\left(\mathrm{N} / \mathrm{m}^{2}\right) \\ \rho & \text { density, }\left(\mathrm{kg} / \mathrm{m}^{3}\right) \\ \Phi & \text { nanoparticles concentration, }(\%)\end{array}$

\section{Acknowledgement}

The authors would like to gratefully acknowledge the Department of Mechanical Engineering in the University if Technology for the financial support of this research.

\section{References}

[1] Ratcliff, J. D., Frozen Sleep: New Frontier in Surgery, Readers Digest, September, p. 93, 2002.

[2] Sjetil S., Therapeutic Hypothermia with Endovascular cooling, Ph. D., and Dept. Anesthesiology unlevel university hospital, Oslo, Norway Scand J Trauma ResuscEmerg Med, 12; 23-25, 2004.

[3] Sebastien F., André B., Paulo R., Jean-A. G., Olivier S., (2011): "Hydraulic and heat transfer study of $\mathrm{SiO} 2 /$ water nanofluids in horizontal tubes with imposed wall temperature boundary conditions, "Universities Joseph Fourier, France Int. J. of Heat and Fluid Flow 32, 424-439.

[4] Choi, U.S, (1998): " Nanofluid technology current status and future", Second Korean-American Scientists and Engineers Association Research Technologies October 22- 24, Vienna, pp 2-21.

[5] Zeinali Herisl, S. Gh. Etamad, M. Nasr Esfahani, (2006): "Heat Transfer Enhancement of Nanfluid Laminar Flow", Iran 14th Annual (Int.) Mechanical Engineering Conference, Isfahan University of Technology, Isfahan, Iran.

[6] Anoop K., Sundararajan T., Sarit K. D., (2009): "Effect of particle size on the convective heat transfer in nanofluid in the developing region", Chennai India Int. J. of Heat and Mass Transfer 52, 2189-2195.

[7] Zhang S., Zhong-yang, Chun-hui, Ming-jiang, (2009): "Heat Transfer Properties of $\mathrm{CuO}$-water Nanofluids in Laminar Flow", Zhejiang University, Hangzhou Zhejiang Province, China, Chin. Soc. for Elec. Eng. Vol. 29 No. 32 Nov. 15.

[8] Byung H. C., Hyun U. K., and Sung H. K., (2008): "Effect of alumina nanoparticles in the fluid on heat transfer in doublepipe heat exchanger system" Department of Chemical and Biological Engineering, Applied Rheology Center, Korea University, Seoul 136-701, Korea Korean J. Chem. Eng., 25 (5), 966-971.

[9] Aghayari, R., Heydar Maddah, Malihe Zarei, Mehdi Dehghani, and Sahar Ghanbari Kaskari Mahalle, Heat Transfer of Nanofluid in a Double Pipe Heat Exchanger, International Scholarly Research Notices, Volume 2014 (2014), Article ID 736424, 7 pages.

[10] Sudarmadji S., A New Correlation for Pressure Drop in, The Cooling Process of AL2O3-Water Nanofluid in Pipes, FME Transactions (2015) 43, 40-46.

$\begin{array}{ll}\text { w } & \text { water } \\ \text { i } & \text { inner } \\ \text { o } & \text { outer } \\ \text { in } & \text { inlet } \\ \text { out } & \text { outlet } \\ \text { c } & \text { coolant }\end{array}$

[11] Mohamed H. Shedid, M. M. Hassan, Numerical Investigation of Heat Transfer Characteristics for the Annular Flow of Nanofluids using YPlus, Journal of Fluid Flow, Heat and Mass Transfer, Volume 3, Year 2016.

[12] Masoud H. F., Mohammad R. T., and Somaye N., (2011): "Numerical and Experimental Investigation OF Heat Transfer OF $\mathrm{ZnO} /$ Water Nan Fluid in the Concentric Tube And Plate Heat Exchangers", Canada, Numerical and Experimental Investigation of Thermal Science, Vol. 15, No. 1, pp. 183-194.

[13] Bozorgan N., Mostafa M. and Nariman B., (2012): "Performance Evaluation of AI2O3/Water Nanofluid as Coolant in a Double-Tube Heat Exchanger Flowing under a Turbulent Flow Regime", Advances in Mechanical Engineering Volume, 8 pages.

[14] MacDonald DA, Pulsatile flow in a catheterized artery, J. Biomech 9: 239-249, 1986.

[15] Back LH, Estimated mean flow resistance increase during coronary artery catheterization, Biomech 27: 169-175, 1994.

[16] Rao AR, Padmavathi K, Mathematical models for catheter movement in blood vessels, GAMS J Math Math Biosci 1: 57-78, 1997.

[17] Back LH, Kwack EY, Back MR, Flow rate-pressure drop relation in coronary angioplasty: Catheter obstruction effect, Trans ASME J Biomech Eng 118: 83-89, 1996.

[18] Dash RK, Jayaraman G, Mehta KN, Estimation of increased flow resistance in a narrow catheterized artery - A theoretical model, J. Biomech 29: 917-930, 1996.

[19] Banerjee RK, Back LH, Back MR, Cho YI, Catheter obstruction effect on pulsatile flow rate-pressure drop during coronary angioplasty, Trans ASME J Biomech Eng 121: 281$289,1999$.

[20] Jason L, Carter L, Greg M and Jennifer A, Modeling Therapeutic Hypothermia Using Heat Exchange Catheter to Cool Blood BEE 4530, Applications to Biomedical Systems. Cambridge, UK: Cambridge UP, Print. 2011.

[21] Rajasekharan, S., V. G. Kubair, and N. R. Kuloor., Heat transfer to non- Newtonian fluids in coiled pipes in laminar flow, International Journal of Heat and Mass Transfer, Vol. 13: $1583-1594,1990$

[22] Hsu, C.-F., and S. V. Patankar., Analysis of laminar nonNewtonian flow and heat transfer in curved tubes, AIChE Journal, Vol. 28 (4): 610-616. 1982.

[23] Rao, B. K., "Turbulent heat transfer to power-law fluids in helical passages., International Journal of Heat and Fluid Flow, Vol. 15 (2): 142-148. 1994.

[24] Escudier, P. J. Oliveira, F. T. Pinho, S. Smith, Fully developed laminar flow of non-Newtonian liquids through annuli: comparison of numerical calculations with experiments, Experiments in Fluids 33, s00348-002-0429-4., 2002. 
[25] Lain William Gouldson, The Flow of Newtonian and NonNewtonian Fluids in an Annular Geometry, Ph. D. Thesis, University of Liverpool by February, 1997.

[26] Wickramasinghe, B. Han, C. M. Kahr., Designing Blood Oxygenators using Blood Mimic Fluids, Department of Chemical Engineering, Colorado State University, Fort Collins, CO, 80523-1370, USA, 2004.

[27] Wickramasinghe S. and Han B., Designing Micro porous Hollow Fiber Blood Oxygenators, Chemical Engineering Research and Design, 83 (A3): 256-267., 2005.

[28] Chhabra R. P. and Richardson J. F., Non-Newtonian Flow in the Process Industries, Fundamentals and Engineering Applications Department of Chemical and Biological Process Engineering, University of Wales, Swansea SA2 8PP, Great Britain, 1999.

[29] Bird, R. B., Armstrong, R. C. and Hassager, O., Dynamics of
Polymeric Liquids,. Vol. 1 Fluid Dynamics, 2nd edn. Wiley, New York, 1997.

[30] Wickramasinghe, S. R., Garcia, J. D. and Han, B., 2002a, Mass and momentum transfer in hollow fiber blood oxygenators, J Membr Sci, 208: 247.

[31] Yuejin Luo, Non-Newtonian Annular Flow and Cuttings Transport through Drilling Annuli at Various Angles, Ph. D. thesis, Department of Petroleum Engineering Heriot-Watt University Edinburgh, U.K. October, 1988.

[32] Sébastien Ferrouillat, André Bontemps a, J. Paulo Ribeiro b, Jean-Antoine Gruss b, Olivier Soriano "Hydraulic and heat transfer study of $\mathrm{SiO}$ /water nanofluids in horizontal tubes with imposed wall temperature boundary conditions"International Journal of Heat and Fluid Flow 32 (2011) 424-439.

[33] Leveque, J., Ann. Mines. 13, 1928, 201, 305, 381. 